\title{
A Novel Procedure to Pursue Aspired Procurement Negotiation Outcomes Using a Combined MADM Model
}

\author{
Chien-Chou Yu $\mathbb{D},{ }^{1}$ Xiang $L i,{ }^{1}$ and Hui $\mathrm{Lu}^{2}$ \\ ${ }^{1}$ Department of Tourism Management, School of Economics and Management, Sanming University, Sanming, \\ Fujian 365004, China \\ ${ }^{2}$ Department of Trade and Economics, School of Economics and Management, Sanming University, Sanming, \\ Fujian 365004, China \\ Correspondence should be addressed to Chien-Chou Yu; chienchouyu@qq.com
}

Received 7 September 2020; Revised 19 December 2020; Accepted 24 December 2020; Published 11 February 2021

Academic Editor: Danielle Costa Morais

Copyright (c) 2021 Chien-Chou Yu et al. This is an open access article distributed under the Creative Commons Attribution License, which permits unrestricted use, distribution, and reproduction in any medium, provided the original work is properly cited.

\begin{abstract}
In the modern global economy, public and private organizations frequently procure goods and services from external suppliers. As such, negotiations are essential to reach procurement agreements and thus achieve organizational objectives and meet criteria in a timely and economically efficient manner. However, numerous relevant studies have revealed that suboptimal agreements frequently occur in procurement negotiation (PN) settings, which negatively affect the realization of business objectives and criteria. This study proposes the addition of a novel procedure that integrates a combined multiple attribute decision-making (MADM) model into the PN framework to identify, measure, and depict suboptimal situations in the context of an influential network relation map (INRM). This approach enables visualized and systematic information to be continuously provided, thus helping to determine possible improvement initiatives for transitioning suboptimal agreements to aspired levels. A real numerical case study is used to demonstrate the practical application of the proposed procedure. The results reveal that by employing the combined MADM model, the proposed procedure can provide managers with a practical foundation for early identification of the critical factors/dimensions for continuous improvement of a negotiated agreement regardless of how or why a suboptimal agreement initially occurs.
\end{abstract}

\section{Introduction}

In the modern cooperative business environment, functions are rarely performed entirely in-house. Public and private organizations must procure goods and services from external suppliers to achieve organizational objectives and criteria in a timely and economically efficient manner [1]. However, managing multiple procurement tasks can be complicated. Procurement typically involves an unclear scope, unforeseen costs, or a long lifespan that requires buyers and sellers to engage in trade-offs of technical, financial, and commercial factors [2]. In such situations, negotiations are commonly used to reach final agreements $[3,4]$. Given that procurement is essential to businesses' success, such negotiations play a critical role in corporate management [5-8].
However, although some procurement decision-makers successfully apply such negotiations to clarify trade terms in formulating mutually beneficial agreements [9], numerous studies have indicated that other negotiated agreements are unable to fully support all aspects of procurement in achieving business objectives [10-12]. For example, in most procurement negotiation (PN) settings, negotiators typically hide information to gain advantages [1]. This opacity of information prevents managers from reaching agreements that ensure optimized business objectives [13]. Additionally, most procurement agreements have a defined lifespan. A time constraint is typically imposed on PN completion [1], which can create pressure and reduce a manager's motivation or ability to fully process, evaluate, and determine all possible alternatives in the pursuance of optimization $[14,15]$. Instead, managers are forced to finalize negotiations 
to achieve suboptimal agreements that create variations, including changed orders and claims, during their implementation $[4,5]$. These studies have implied that suboptimal agreements occur frequently in the PN setting.

A practical survey by Turner and Keegan [12] indicated that an agreement is merely a tentative settlement, which by its nature is incomplete; further improvements are always required later during the process of implementation. More comprehensively, Ertel [11] analyzed hundreds of complex negotiation projects and concluded that "countless deals that were signed with optimism fall apart during implementation, despite the care and creativity with which their terms were crafted." His study emphasized how decisions made in a negotiated agreement can be affected by future trends, and he also highlighted the need for continuous improvement to facilitate optimal results for the business objectives and criteria. Kujala et al. [3] examined negotiated agreements from the perspectives of sales and implementation and highlighted the importance of improving joint decisions between buyers and sellers over a transaction's lifecycle. Yang et al. [16] argued that negotiated agreements cause the most substantial project delays, which in turn create serious conflicts during and after implementation of such agreements. These studies have suggested that an efficient approach is required to improve the implementation of negotiated agreements.

The relevant literature on how to settle suboptimal negotiated agreement problems can be traced back to 1985 , when Raiffa [17] argued that the majority of negotiated agreements have the potential for improvement. His study also proposed a postsettlement settlement concept that encourages negotiators to use the negotiated agreement as a foundation to seek additional value. Based on Raiffa's concepts, Susskind [18] argued that pos-settlement settlement can be applicable under cooperative negotiation, in which the negotiating parties treat each other as partners and share information. William [19], who adopted a macroperspective, suggested that monitoring and evaluation of negotiated agreements should be viewed as an essential part of the negotiation process. Smolinski and Xiong [20] concluded that postsettlement settlement is a critical negotiation competency to manage conflicts in the increasingly complex modern business environment. These studies have introduced several helpful ideas to address the problems that are associated with negotiated agreements. However, based on this study's literature review, these ideas have not been developed into an operational procedure for practical use.

This study proposes a novel procedure that integrates a hybrid multiattribute decision-making (HMADM) model into the PN framework to increase the ability of negotiated agreements to obtain optimal PN outcomes during their implementation. The HMADM model was originally introduced by Tzeng to solve decision problems in interdependent situations [21]. The HMADM model provides theoretical suggestions for how to continuously improve decision implementation toward aspired levels [22-25], and thus, its use is appropriate for this study. The proposed procedure enables the identification, measurement, and depiction of suboptimal agreements in a context of the influence network relation map (INRM). The INRM provides managers with visualized and systematic information to easily analyze index gaps among factors, dimensions, and the overall agreement to pursue the aspired PN outcomes. This study uses a numerical example to demonstrate the functionalities of the proposed procedure. The results of the HMADM model revealed that the proposed procedure can provide managers with a critical foundation for the early identification of the critical factors and dimensions of a negotiated agreement, which are needed to continuously improve outcomes, regardless of how and why a suboptimal agreement initially occurs. The remainder of this study is arranged as follows. Section 2 reviews the literature on the $\mathrm{PN}$ process. Section 3 introduces the HMADM model comprising the DEMATEL method, the DEMATEL-based analytic network process, and the modified VIKOR method. Section 4 discusses the proposed procedure. Section 5 demonstrates the operation of the proposed procedure by examining a real-world numerical example and discusses the results. Section 6 provides conclusions and further remarks.

\section{Literature Review}

In practice, negotiations can be characterized differently depending on specific business situations. PNs can occur between buyers and sellers at numerous points in the procurement process. However, this study emphasizes how to improve negotiated agreements during the implementation of such agreements and when two parties have multiple issues in play. Additionally, this study assumes that the parties involved in $\mathrm{PN}$ intend to obtain and implement favorable agreements to produce aspired outcomes and thus fulfil their procurement objectives and criteria.

Typically, PN follows a three-phase framework adopted by procurement professionals worldwide [1] comprising prenegotiation, meeting, and postnegotiation (Figure 1).

Prenegotiation starts with issues that the negotiating parties disagree about, such as time, cost, scope, and quality [26]. In the PN environment, if any of these issues or dimensions change, at least one other issue or dimension is likely to be influenced. For example, if the procurement time is reduced, costs often rise due to the additional resources needed to complete the same scope of procurement in a shorter time. If a budget increase is not possible, both procurement scope and desired quality may be reduced. Negotiators must consider these mutually interdependent situations to prepare a set of alternatives to finalize negotiations in each PN phase [1].

Two types of negotiating strategies are most common: win-lose and win-win. In a win-lose situation, each party seeks a maximized share of a fixed amount of resources. In a win-win negotiation, one party's gain does not necessarily come at the other's expense [13]. In most PN settings, a winlose strategy typically emerges early in the negotiation process, but communication and information sharing can transform this into a win-win situation [27]. During the meeting phase, negotiators present their initial offers and then decide whether to make concessions based on a package or separately [3]. Determining and offering the right options 


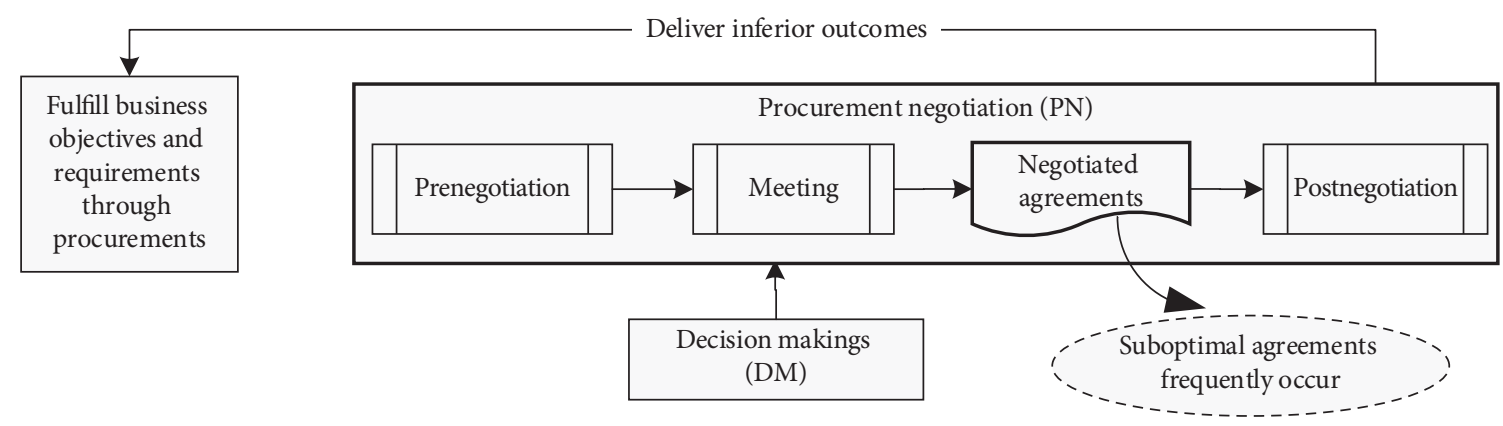

FIgURE 1: General PN framework.

can provide flexibility and expedite the negotiation process. A range of decision-making methods have therefore been developed to streamline option selection in negotiations [5].

Keeney and Raiffa [28] proposed a utility function to model negotiator preferences. Rubinstein [29] proposed the use of alternating-offer bargaining in his analysis of negotiation game outcomes. Following these studies, many researchers have proposed negotiation decision aids [30]. Teich et al. [31] classified these decision-aid models into four categories: (a) value function-based and concession-based models; (b) value function-based and Pareto-improvementseeking models; (c) interactive concession-making models; and (d) interactive Pareto-improvement models. Most decision-aid models emphasize the determination of a Paretooptimal solution through concessions [32] under limited resources (which are presumably subject to constraints). However, limited resources impose difficulties in determining the Pareto frontier to seek optimal solutions, resulting in suboptimal agreements that deliver inferior outcomes in the conventional approach [20]. To fulfil the shortcomings, Tzeng and Huang [33] proposed a hybrid multiple attribute decision-making (HMADM) model to pursue aspired decision outcomes through continuous improvements.

The HMADM model employs a decision-making trial and evaluation laboratory (DEMATEL) technique [34], which allows for interinfluential effects to be identified between the decision factors/dimensions (or objectives/ criteria) on an influential network relations map (INRM). Second, this model applies an analytic network process (ANP) [35] to transform the DEMATEL interinfluential values into influential weights (IWs), so as to be able to better prioritize the decision-making criteria, a procedure called a DEMATEL-based ANP (DANP). Third, this model employs an "aspiration level" principle to modify the multicriteria optimization and compromise solution method, named "ViseKriterijumska Optimizacija I Kompromisno Rešenje" in Serbian (called the "modified VIKOR method") [36], to avoid "choosing the best among inferior options/alternatives," [33]. The aspiration level concept was proposed by Simon [37], who argued that actual human decision-making behavior is a sequential process, and a decision-maker is satisfied when a selected alternative aligns with an aspiration level criterion, which is the highly desirable outcome level. Therefore, the modified VIKOR method replaces the traditional $\mathrm{max} / \mathrm{min}$ approach (choosing relatively good solutions from existing alternatives) with an aspiration level, which enables a shift from ranking and selection when determining the most preferable alternative to attaining performance improvements based on the INRM [36]. By combining these aforementioned concepts and procedures, the HMADM model can provide managers with systematic visual information to allow for the identification of the critical factors needed to enact improvement strategies that would better enable the aspired outcomes to be reached [21].

Currently, behaviors, models, and support systems associated with multiple criteria group decision-making and negotiations remain a prominent research topic for a wide range of applications [38, 39]. For example, Frej et al. [40] proposed a decision support tool based on the FITradeoff method to expertise agreement achievement for multiple criteria group decision-making with situations of partial/ incomplete/imprecise information. Their study has also indicated the usefulness of graphical visualization techniques in collective decision-making processes. With these advanced studies, negotiators enable to apply new methods and tools to reduce the level of uncertainties in evaluating, ranking, and selecting alternative offers and counteroffers in obtaining group consensus at different stages within a negotiation process.

In the postnegotiation phase, both parties implement and administer the negotiated agreement in an attempt to achieve the aspired outcomes and to satisfy the determined performance objectives and criteria [11]. However, suboptimal negotiated agreements frequently occur, and the parties involved typically hold meetings to discuss related issues such as performance gaps, possible changes, and improvement requirements $[17,19]$. Generally, these meetings can foster closer relationships between the parties and increase mutual trust through information sharing [13]. Additionally, implementing such agreements often takes a long time. In the cloud-computing era, new technologies and management mechanisms emerge on an almost daily basis [41]. Accordingly, in contrast to traditional negotiations that follow a suboptimal agreement, the modern postnegotiation phase provides opportunities to create additional value.

Research has indicated that adding value to a negotiated agreement requires additional effort to evaluate problems 
and to generate a comprehensive list of potential options from which workable solutions can be selected [13]. Additionally, the negotiating parties must constantly assess the implementation of the agreement and maintain proactive communications to determine possible improvements [16]. As such, the next section proposes a novel procedure to analyze and improve on suboptimal outcomes in the postnegotiation phase within the PN setting.

\section{A Novel Procedure to Pursue Aspired PN Outcomes}

This section first briefly introduces the essential concepts and computational equations related to the DEMATEL method, DANP, and the modified VIKOR method. Next, it explains the proposed procedure.

3.1. The DEMATEL Method. The DEMATEL method was developed by the Battelle Geneva Institute in 1972 for assessing and solving complex groups of problems. This method uses Boolean operations and Markov processes [34] to measure cause and effect relationships in each dimension or criterion within a system (or subsystem). Quantitative measurements are then mapped onto an INRM-representing problem structure with a visual rout exhibiting the degree and direction in which each dimension or criterion influences the overall system performance. This method has been widely applied to help managers easily obtain valuable information for practical improvements in fields such as security systems and aerospace services [26, 33]. The computational steps for the DEMATEL method are described as follows.

Step 1. Obtain the initial average influence relation matrix A. This step uses a team comprising $E$ experts to identify the number of factors or criteria, $n$, in a system. Each expert measures the degree of influence that factor $i$ has on factor $j$ in achieving system objectives. Typically, the measurement scale ranges from 0 to 4 , with 0 representing "absolutely no influence," 1 representing "low influence," 2 representing "medium influence," 3 representing "high influence," and 4 representing "very high influence." Through pairwise comparisons, the results of all expert measurements are denoted as matrix $\mathbf{H}^{e}=\left[h_{i j}^{e}\right]$, where $e=1,2, \ldots, E$, and $E$ is the number of experts. By averaging the matrix $\mathbf{H}^{e}=\left[h_{i j}^{e}\right]$, the initial average influence relation matrix $\boldsymbol{A}$ can be obtained, as illustrated by

$$
\mathbf{A}=\left[a_{i j}\right]_{n \times n},
$$

where $a_{i j}=\sum_{e=1}^{E}\left(h_{i j}^{e} / E\right)$, and $h_{i j}^{e}$ is the measurement by $e$ th expert in $\mathbf{H}^{e}$.

Step 2. Obtain the normalized influence relation matrix $\mathbf{D}$. By using A [ ], the normalized influence relation matrix $\mathbf{D}$ can be obtained as shown in

$$
\mathbf{D}=\frac{\mathbf{A}}{s}=\left[d_{i j}\right]_{n \times n},
$$

where $s=\max \left(\max _{1 \leq i \leq n} \sum_{j=1}^{n} a_{i j}, \max _{1 \leq i \leq n} \sum_{i=1}^{n} a_{i j}\right)$.

Step 3. Obtain the total influence relation matrix $\mathbf{T}$. Through the matrix operation of $\mathbf{D}$, the total influence relation matrix $\mathrm{T}$ can be obtained as shown in

$$
\mathbf{T}=\mathbf{D}(\mathbf{I}-\mathbf{D})^{-1}, \quad \text { when } u \longrightarrow \infty, \lim _{u \longrightarrow \infty} \mathbf{D}^{u}=[0]_{n \times n},
$$

where $\mathbf{I}$ is an identity matrix, $\mathbf{D}=\left[d_{i j}\right]_{n \times n}, 0 \leq d_{i j} \leq 1$, $0 \leq \sum_{i} d_{i j} \leq 1,0 \leq \sum_{j} d_{i j} \leq 1$ and at least one column or one row of summation but not every column or row equals one; then, $\lim _{u \longrightarrow \infty} \mathbf{D}^{u}=[0]_{n \times n}$ can be guaranteed.

Step 4. Obtain the INRM. Based on the matrix T, the INRM can be constructed using the following substeps (SSs):

SS 4-1. Define each row sum and column sum of matrix $T$ as a respective $n \times 1$ vector, as shown in the following equations:

$$
\begin{aligned}
& \mathbf{r}=\left[r_{i}\right]_{n \times 1}=\left[\sum_{j=1}^{n} t_{i j}\right]_{n \times 1}, \\
& \mathbf{c}=\left[c_{j}\right]_{1 \times n}^{\prime}=\left[\sum_{t=1}^{n} t_{i j}\right]_{1 \times n}^{\prime}=\left[c_{j}\right]_{n \times 1},
\end{aligned}
$$

where $r_{i}$ indicates the total influence that factor $i$ has on the all other factors and $c_{j}$ indicates the total influence that the all other factors have on factor $j$ for $i, j=1,2$, ..., $n$; the superscript ' denotes the transpose.

SS 4-2. Compute $r_{i}+c_{j}$ and $r_{i}-c_{j}, i, j \in\{1,2, \ldots, n\}$. When $i=j, r_{i}+c_{i}$ provides an index representing the strength of the total influence that each factor exerts on and receives from the others; that is, $r_{i}+c_{i}$ indicates the centrality of the role that factor $i$ plays in the system. In addition, $r_{i}-c_{i}$ indicates the net influence that factor $i$ contributes to the system. If $\left(r_{i}-c_{i}\right)$ is positive, factor $i$ influences the other factors, and if $\left(r_{i}-c_{i}\right)$ is negative, factor $i$ is influenced by the other factors.

SS 4-3. Plot the dataset $\left[\left(r_{i}+c_{i}\right),\left(r_{i}-c_{i}\right)\right]$ into the INRM to visualize the structure of the interrelationship among all factors related to the system performance; this plot reveals valuable information for problem solving.

3.2. DANP. DANP can be described as DEMATEL-based ANP. ANP was proposed by Saaty [35] to address interdependence and feedback among the factors, dimensions, or alternatives associated with a decision-making problem. By applying the basic concept of ANP to formulate the influence relation matrix obtained from the DEMATEL method, DANP can derive the influence weights (IWs) among a set of interrelated factors for superior communication of real interdependent problematic situations, improvement alternatives, and decisions [33]. DANP's operational steps are described as follows. 
Step 5. Obtain an unweighted supermatrix. This step involves the following three SSs:

SS 5-1. Classify all factors in the total influence relation matrix $\mathbf{T}$ (see Step 3) into the appropriate dimensions (clusters) to form a new matrix, which is referred to as the total influence relation matrix of factors, $\mathbf{T}_{C}$, as shown in equation (6), where $\sum_{j=1}^{m} m_{j}=n, m<n$, and $\mathbf{T}_{c}^{i j}$ is an $m_{i} \times m_{j}$ matrix.

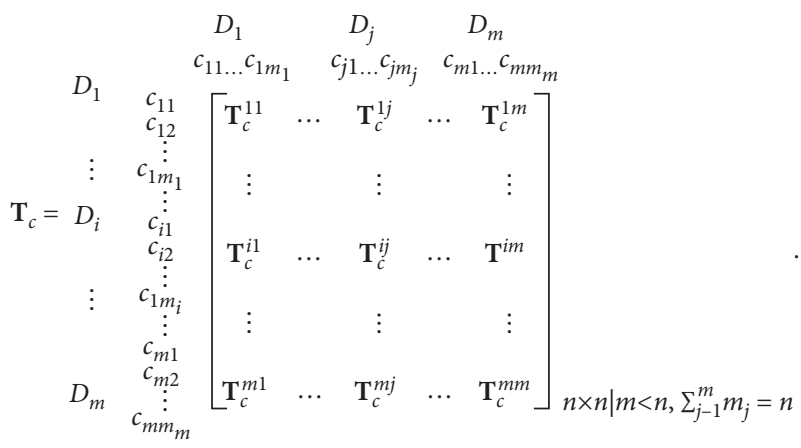

SS 5-2. Normalize each dimension (cluster) of criteria by its total degree of effect to obtain a matrix, which is referred to as the normalized total influence relation matrix of factors, as demonstrated in

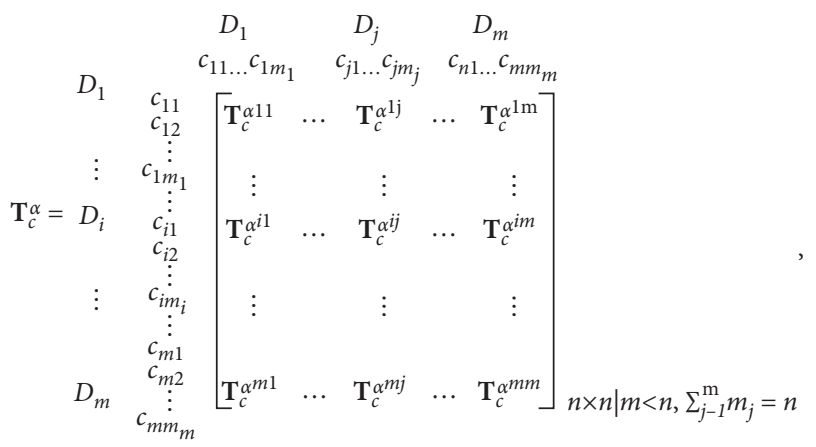

where $\mathbf{T}_{C}^{\alpha 11}$ is calculated as shown in equation (8). The other elements, $\mathbf{T}_{C}^{\alpha i j}$, can be obtained using the same method.

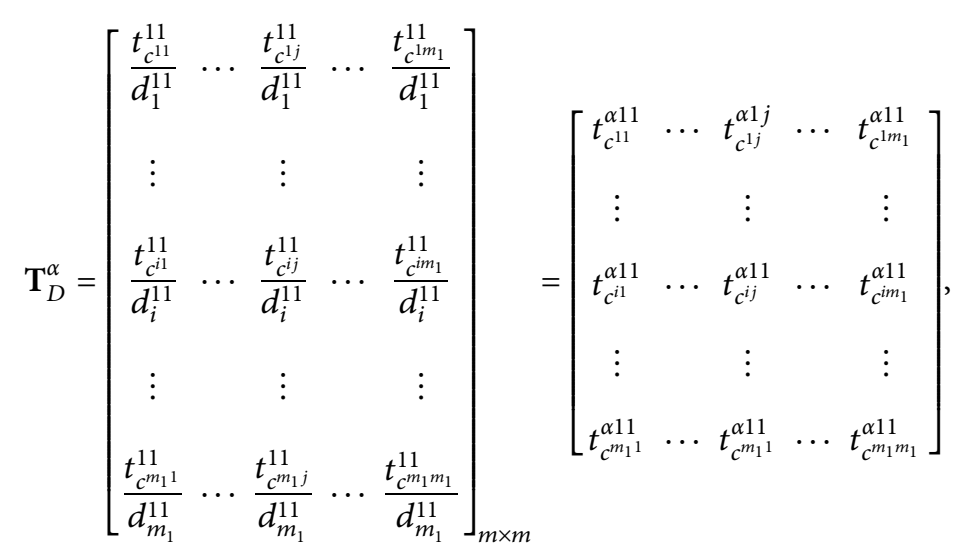


where $d_{c i}^{11}=\sum_{j=1}^{m 1} t_{i j}^{11}, i=1,2, \ldots, m_{1}$
SS 5-3. Transpose $\mathbf{T}_{C}^{\alpha}$ into an unweighted supermatrix $\mathbf{W}$ according to the dependent relationship in the dimension (cluster), as shown in

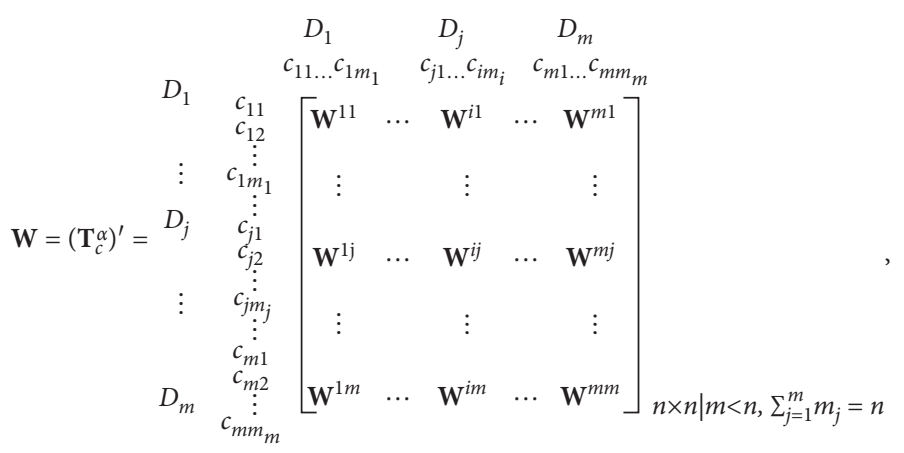

where $\mathbf{W}^{11}$ is calculated as indicated in equation (10). The other $\mathbf{W}^{i j}$ can be obtained using the same method. If a blank space or a zero appears in the matrix, the dimension or factor is independent.

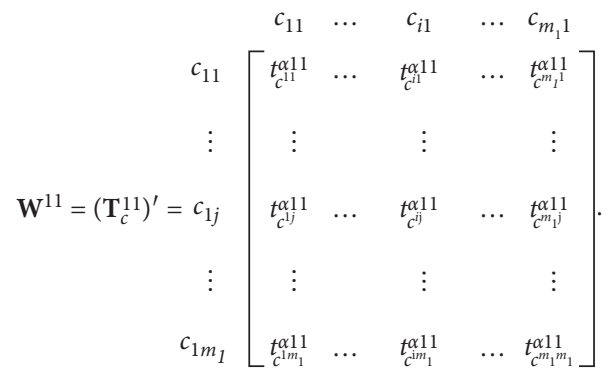

Step 6. Obtain the weighted supermatrix. This involves the following three SSs:

SS 6-1. Based on equation (6) in SS 5-1, each dimension in $\mathbf{T}_{C}$ is grouped as the total influence relation matrix of dimensions $\mathbf{T}_{D}$ by using

$$
\mathbf{T}_{D}=\left[\begin{array}{ccccc}
t_{D}^{11} & \cdots & t_{D}^{1 j} & \cdots & t_{D}^{1 m} \\
\vdots & & \vdots & & \vdots \\
t_{D}^{i 1} & \cdots & t_{D}^{i j} & \cdots & t_{D}^{i m} \\
\vdots & & \vdots & & \vdots \\
t_{D}^{m 1} & \cdots & t_{D}^{m j} & \cdots & t_{D}^{m m}
\end{array}\right]_{m \times m}
$$

SS 6-2. Normalize each dimension in $\mathbf{T}_{D}$ with respect to the total degree of the effects and obtain the normalized total influence relation matrix of dimensions $\mathbf{T}_{D}^{\alpha}$, as shown in

$$
\begin{aligned}
& \mathbf{T}_{D}^{\alpha}=\left[\begin{array}{ccccc}
\frac{t_{D}^{11}}{d_{1}} & \cdots & \frac{t_{D}^{1 j}}{d_{1}} & \cdots & \frac{t_{D}^{1 m}}{d_{1}} \\
\vdots & & \vdots & & \vdots \\
\frac{t_{D}^{i 1}}{d_{i}} & \cdots & \frac{t_{D}^{i j}}{d_{i}} & \cdots & \frac{t_{D}^{i m}}{d_{i}} \\
\vdots & & \vdots & & \vdots \\
\frac{t_{D}^{m 1}}{d_{m}} & \cdots & \frac{t_{D}^{m j}}{d_{m}} & \cdots & \frac{t_{D}^{m m}}{d_{m}}
\end{array}\right]_{m \times m} \\
& =\left[\begin{array}{ccccc}
t_{D}^{\alpha 11} & \cdots & t_{D}^{\alpha 1 j} & \cdots & t_{D}^{\alpha 1 m} \\
\vdots & & \vdots & & \vdots \\
& & & & \\
t_{D}^{\alpha i 1} & \cdots & t_{D}^{\alpha i j} & \cdots & t_{D}^{\alpha i m} \\
\vdots & & \vdots & & \vdots \\
t_{D}^{\alpha m 1} & \cdots & t_{D}^{\alpha m j} & \cdots & t_{D}^{\alpha m m}
\end{array}\right]_{m \times m}
\end{aligned}
$$

where $d_{i}=\sum_{j=1}^{m} t_{D}^{i j}, i=1,2, \ldots, m$.

SS 6-3. Based on equations (9) and (12), the weighted supermatrix can be obtained using equation (13), where $t_{i j}^{\alpha D}$ is a scalar and $\sum_{j=1}^{m} m_{j}=n$. 


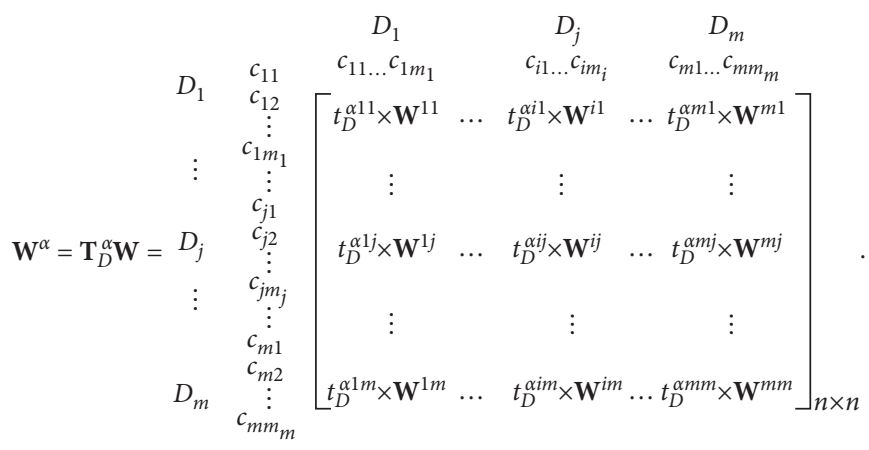

Step 7. Limit the weighted supermatrix. This step involves multiplying the weighted supermatrix $\mathbf{W}^{\alpha}=\left[w_{i j}\right]_{n \times n}$ by itself, denoted as $\left(\mathbf{W}^{\alpha}\right)^{z}$, until $\left(\left[w_{i j}\right]_{n \times n}\right)^{2}$ converges to some other value that is the same for all instances of $j$. Using $\lim _{z \longrightarrow \infty}\left(\mathbf{W}^{\alpha}\right)^{z}$, the IWs of factors can be obtained as follows: $\mathbf{w}=\left(w_{1}, \ldots, w_{j}, \ldots, w_{n}\right)$.

3.3. Modified VIKOR. The VIKOR method was proposed by Opricovic [42] to solve problems that involve incommensurable and conflicting factors. Originally, this method focused on analyzing a set of alternatives and selecting a compromise solution closest to the ideal state $[36,43]$. The ideal state was defined as a set of maximum or minimum values related to the benefit or cost criteria for all alternatives, if performance values $\left\{f_{k j} \mid k=1,2, \ldots, K\right\}$ exhibited $k$ alternatives in the $j$ th criterion, where higher is better, and then $f_{j}^{*}=\max \left\{f_{k j} \mid k=1,2, \ldots, K\right\}$ and $f_{j}^{-}=$ $\min \left\{f_{k j} \mid k=1,2, \ldots, K\right\}$ in the conventional approach (i.e., "max-min" as the benchmark). However, these traditional compromises can lead to situations of "choosing the best among inferior options/alternatives"; hence, Tzeng and Huang [33] proposed the modified VIKOR method to replace the maximum/minimum approach with the "aspired worst" method, in which $f_{j}^{\text {aspired }}=10$ and $f_{j}^{\text {worst }}=0$ are set as the aspired level and the worst level, respectively, for criterion $j$, if the questionnaire scores range from 0 ("complete dissatisfaction/bad") to 10 ("extreme satisfaction/good"). Recently, this method has been used to aid decision-makers in identifying critical gaps in need of further improvement [44]. Details regarding the operational steps of the modified VIKOR method are presented as follows.

Step 8. Obtain an aspired or tolerable level. Assume that a problem with $K$ alternatives denoted as $A_{1}, A_{2}, \ldots A_{k}$, $\ldots A_{K}$ is evaluated using $n$ factors. The performance value of alternative $A_{k}$ with respect to the $j$ th factor is denoted as $f_{k j}$, and the IW of the $j$ th factor is denoted as $w_{j}$ obtained using DANP, where $j=1,2, \ldots, n$. Then, the best value (aspired level) $f_{j}^{\text {aspired }}$ and worst value $f_{j}^{\text {worst }}$ are determined for all criteria $j=1,2, \ldots, n$, and the original ratings $f_{k j}$ are transformed into normalized gap-ratings, as shown in

$$
r_{k j}=\frac{\left|f_{j}^{\text {aspired }}-f_{k j}\right|}{\left|f_{j}^{\text {aspired }}-f_{j}^{\text {worst }}\right|} .
$$

Step 9. Compute the mean of group utility $S_{k}$ (average value) and maximal regret $Q_{k}$ (priority improvement). In this step, $S_{k}$ indicates the synthesized gaps based on the weighted average operations from each factor into specific dimensions and overall. $Q_{k}$ indicates the maximal gap of $k$ alternatives in each dimension and the overall for the priority improvement. The values of $S_{k}$ and $Q_{k}$ are computed as presented in the following equations:

$$
\begin{aligned}
L_{k}^{p=1} & =S_{k}=\sum_{j=1}^{n} w_{j} r_{k j} \\
& =\sum_{j=1}^{n} w_{j}\left(\frac{\left|f_{j}^{\text {aspired }}-f_{k j}\right|}{\left|f_{j}^{\text {aspired }}-f_{j}^{\text {worst }}\right|}\right), \quad k=1,2, \ldots K,
\end{aligned}
$$

where $w_{j}$ are the influential weights of the criteria from DANP.

$$
L_{k}^{p=\infty}=Q_{k}=\max _{j}\left\{r_{k j} \mid j=1,2, \ldots, n\right\}, \quad k=1,2, \ldots, K .
$$

Step 10. Compute the index value. The index values are computed using the relation as shown in

$$
R_{k}=v \frac{\left(S_{k}-S^{\text {aspired }}\right)}{S^{\text {worst }}-S^{\text {aspired }}}+(1-v) \frac{\left(Q_{k}-Q^{\text {aspired }}\right)}{Q^{\text {worst }}-Q^{\text {aspired }}},
$$

where $k=1,2, \ldots, K$, and setting " $S$ aspired $=\min _{k} S_{k}$ and $Q^{\text {aspired }}=\min _{k} Q_{k}$ " and " $S^{\text {worst }}=\max _{k} S_{k}$ and $Q^{\text {worst }}=$ $\max _{k} Q_{k}$ ". We can also assume that $S^{\text {aspired }}=0$ and $Q^{\text {aspired }}=$ 0 (when all criteria are achieved up to the aspiration level, completely and without gaps as the target) and that $S^{\text {worst }}=1$ and $Q^{\text {worst }}=1$ (i.e., all criteria are as in the worst situations); $v$ is presented as the weight of the strategy for paying attention to the average gap $S_{k}$ (i.e., the maximum group utility in how the gap nears zero), or paying attention $(1-v)$ to punishing gap $Q_{k}$ which is the maximized gap criterion (i.e., the individual regret/gap) that should be prioritized for improvement. As such, equation (17) can be rewritten as 
equation (18) to measure the gaps with dual ranking and selecting criteria.

$$
R_{k}=v S_{k}+(1-v) Q_{k}
$$

where $S^{\text {aspired }}=0, S^{\text {worst }}=1, Q^{\text {aspired }}=0$, and $Q^{\text {worst }}=1$.

Step 11. Rerank or improve the alternatives for a compromise solution. In this step, the values $S_{l}, Q_{l}$, and $R_{l}$ for $l=1,2, \ldots, K$ are sorted in decreasing order, and a compromise solution is presented based on the alternatives $A^{(1)}, A^{(2)}, \ldots A^{(l)}, \ldots A^{(k)}$ by applying equation (17). Finally, the performance gaps in each factor, each dimension, and the overall system that correspond to the compromise solution are measured using equations (15) and (16).

3.4. Development of the Proposed Procedure. This section introduces how the MADM method is integrated into the PN setting to evaluate the dependency relationships and performance gaps in a negotiated agreement for obtaining the aspired PN outcomes. Figure 2 is a graphical representation of the proposed procedure. As presented in Figure 2, the proposed procedure first organizes a team of experts familiar with the procurement project under negotiation. The experts then identify and determine strategies to improve all factors that may impair the realization of the procurement objectives, dimensions, and criteria during the postnegotiation stage. More specifically, the proposed approach comprises four main stages: (1) identification of factors (criteria) to be improved using the expert team; (2) evaluation of interinfluential effects at all tiers using the DEMATEL method to reveal the degree and direction of each factor's influence upon the aspired objectives or criteria; (3) computation of the IW of each factor or dimension using DANP to determine at which priority level they help reduce the performance gaps; and (4) measurement of the gap indices using the modified VIKOR method. We then integrate the measurements with the weights on the INRM, thus providing managers with systematic tools for determining how to implement continuous improvement. The next section demonstrates the proposed procedure in practice.

\section{Application of the Proposed Procedure to a Real Numerical Example: Results and Discussion}

This section examines a logistics service project operating in both the public and private sectors to demonstrate the proposed procedure's functionality in a $\mathrm{PN}$ setting. To preserve project information confidentiality, all data are transformed into equivalent units.

4.1. Background. The case study organization (hereafter referred to as the buyer) has implemented a logistics transformation policy by outsourcing part of its organic workload to domestic private contractors. This policy requires potential contractors to ensure that support systems are reliable, available, and maintainable by the end users. Due to the limited number of suppliers in the market, such logistics service projects are executed through sole-source procurement by negotiation. One example is a three-year logistics support service for a TA helicopter that the buyer purchases from Company B (hereafter referred to as the seller) in a PN context. During the meeting phase of the negotiation, the seller disagrees with the supportability deployment level of several subsystems requested by the buyer. To meet the end user's deadline, the buyer accepts the seller's offered supportability. However, the compromiselevel agreement contains performance gaps that could negatively impact the buyer's operations. Therefore, the buyer asks the seller to implement improvements over the 3year service period. The seller claims that because this necessitates additional resources, they cannot guarantee improvements to all subsystems. Meanwhile, the seller asks the buyer to submit a proposal for further consideration. The buyer applies this study's proposed procedure to obtain a proposal to satisfactorily settle the problems that result from the suboptimal negotiated agreement.

4.2. Application of the Proposed Procedure. This section describes how the buyer follows the proposed procedure to pursue its aspired PN outcomes.

\subsubsection{Identification of Factors to be Improved Using an Expert} Team. The buyer forms a team of experts from its departments in charge of logistics (two experts), procurement (one expert), finance (one expert), end users (two experts), and project management (two experts), all of whom have considerable backgrounds in this project. The team members analyze the negotiated agreement and the pertinent information, determining that three main systems (dimensions) of the 12 subsystems (factors or criteria) contain performance gaps that require improvement in the deployment level of supportability (Table 1). Table 1 illustrates the three different levels of supportability under the buyer's consideration on each respective subsystem in terms of its operations. The threshold is the lowest level of supportability (minimized criteria) required by the buyer, the deployment is the highest level of supportability (maximized criteria) that the buyer expects to obtain, and the negotiated level of supportability is what the buyer and the seller agree on. Additionally, the gaps to be improved are the differences between the negotiated level and the deployment level that the buyer requests from the seller during implementation of the agreement.

4.2.2. Evaluation of Interinfluential Effects Using the DEMATEL Method. As illustrated in Table 1, the team members aggregate the analytical results in the 12 -by-12 matrix of initial average influence relations $\mathbf{A}$ (Table 2) by using equation (1). The initial average influence relation matrix is further normalized to obtain matrix $\mathbf{D}$ (Table 3 ) by using equation (2). Subsequently, the team members calculate a total influence relation matrix $\mathbf{T}$ by using equation 


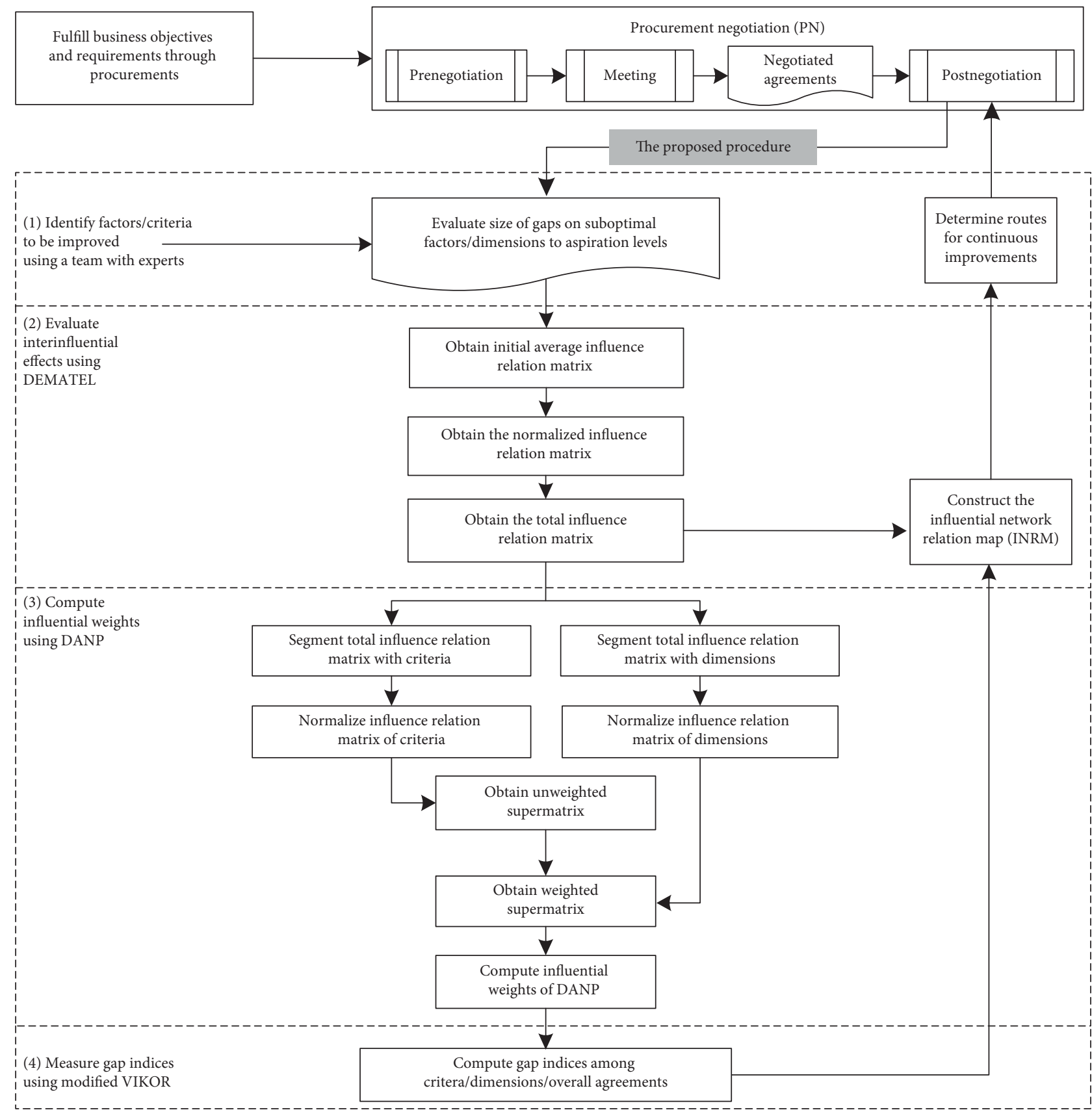

Figure 2: Proposed procedure.

(3). They then use equation (6) to classify the 12 factors and three dimensions to obtain a total influence relation matrix of factors or criteria $\mathbf{T}_{C}$, after which equation (11) is used to obtain a total influence relation matrix for dimensions $\mathbf{T}_{D}$. The results are summarized in Table 4 . In matrix $\mathbf{T}$, the inconsistency rate of the evaluation results from the experts is only $1.16 \%$, which is much lower than $5 \%$. This result implies that the inclusion of an additional expert would not influence the findings and that the results are significant at a confidence level of $98.84 \%$.

Table 4 illustrates the degree of total influence that a factor exerts on the other factors using equation (4) and the degree of total influence received by a factor from the other factors using equation (5). The results are summarized in Table 5, which also presents role centrality $\left(r_{i}+c_{i}\right)$ and net influence $\left(r_{i}-c_{i}\right)$ for the factors and dimensions. Based on these values, the buyer establishes an INRM illustrating the degrees and directions of interinfluential effects between the 12 factors in the three dimensions associated with the supportability deployment level for the mission operations (Figure 3).

For example, in the airframe dimension $\left(D_{1}\right.$; upper right in Figure 3), the $x$-coordinate is the role centrality $\left(r_{i}+c_{i}\right)$, and the $y$-coordinate is the net influence $\left(r_{i}-c_{i}\right)$. First, with reference to Table 5 , we determine the values for the airframe $\left(D_{1}\right)$, electrics $\left(D_{2}\right)$, and weapon $\left(D_{3}\right)$ dimensions, which are 
TABle 1: Expert-identified improvement factors.

\begin{tabular}{|c|c|c|c|c|c|}
\hline \multicolumn{2}{|c|}{ Dimensions and factors/criteria } & \multicolumn{4}{|c|}{ Supportability (\%) } \\
\hline Main systems (dimensions) & Subsystems (factors/criteria) & Threshold & Deployment & Negotiated & Gaps to be improved \\
\hline \multirow{7}{*}{ Airframe (7) } & Landing gear (LG) & 76 & 85 & 78 & 7 \\
\hline & Hydraulics system (HS) & 78 & 86 & 80 & 6 \\
\hline & Fuel system (FS) & 80 & 88 & 83 & 5 \\
\hline & Assistant power units (APU) & 78 & 84 & 80 & 4 \\
\hline & Structure system (SS) & 78 & 86 & 79 & 7 \\
\hline & Transmission system (TS) & 76 & 84 & 78 & 6 \\
\hline & Flight control system (FCS) & 75 & 83 & 77 & 6 \\
\hline \multirow{2}{*}{ Electrics (2) } & Communication system (CS) & 80 & 84 & 83 & 1 \\
\hline & Radio system (RDS) & 82 & 87 & 85 & 2 \\
\hline \multirow{3}{*}{ Weapons (3) } & Missile system (MS) & 79 & 81 & 80 & 1 \\
\hline & Rocket system (RS) & 85 & 88 & 86 & 2 \\
\hline & Gun system (GS) & 84 & 89 & 87 & 2 \\
\hline
\end{tabular}

TABLE 2: Initial average influence relation matrix $\mathbf{A}=\left[a_{i j}\right]_{n \times n}$ obtained using the DEMATEL method.

\begin{tabular}{lcccccccccccc}
\hline A & LD & HS & FS & APU & SS & TS & FCS & CS & RDS & MS & RS & GS \\
\hline LD & 0.0000 & 1.1250 & 1.6250 & 1.6250 & 3.0000 & 2.0000 & 1.1250 & 0.3750 & 0.3750 & 0.3750 & 0.3750 & 0.3750 \\
HS & 3.6250 & 0.0000 & 3.8750 & 3.7500 & 2.0000 & 3.5000 & 3.5000 & 1.7500 & 1.7500 & 3.1250 & 3.0000 & 2.8750 \\
FS & 2.6250 & 3.6250 & 0.0000 & 1.3750 & 1.2500 & 1.2500 & 1.3750 & 1.2500 & 1.2500 & 1.2500 & 1.2500 & 1.1250 \\
APU & 3.5000 & 3.0000 & 2.8750 & 0.0000 & 2.0000 & 2.8750 & 3.1250 & 1.8750 & 1.8750 & 2.8750 & 2.0000 & 1.0000 \\
SS & 2.3750 & 1.8750 & 2.1250 & 3.0000 & 0.0000 & 2.8750 & 2.2500 & 2.0000 & 1.8750 & 2.8750 & 2.8750 & 2.7500 \\
TS & 2.0000 & 2.7500 & 2.7500 & 2.8750 & 2.0000 & 0.0000 & 2.8750 & 1.0000 & 1.0000 & 1.8750 & 1.8750 & 1.8750 \\
FCS & 2.0000 & 2.1250 & 2.0000 & 3.0000 & 1.0000 & 2.0000 & 0.0000 & 3.0000 & 3.8750 & 3.1250 & 3.0000 & 2.8750 \\
CS & 1.2500 & 0.3750 & 1.0000 & 0.3750 & 1.8750 & 1.0000 & 3.1250 & 0.0000 & 4.2500 & 2.6250 & 2.6250 & 3.0000 \\
RDS & 1.1250 & 0.2500 & 0.8750 & 0.2500 & 1.7500 & 0.8750 & 3.0000 & 3.7500 & 0.0000 & 2.8750 & 2.8750 & 2.8750 \\
MS & 0.6250 & 1.7500 & 0.8750 & 1.7500 & 1.7500 & 1.0000 & 1.8750 & 1.0000 & 1.0000 & 0.0000 & 2.5000 & 2.5000 \\
RS & 0.6250 & 1.0000 & 0.8750 & 0.8750 & 1.7500 & 1.0000 & 1.0000 & 1.0000 & 1.0000 & 2.6250 & 0.0000 & 2.8750 \\
GS & 0.6250 & 0.8750 & 0.8750 & 0.8750 & 1.8750 & 1.0000 & 1.1250 & 0.8750 & 1.0000 & 2.6250 & 3.1250 & 0.0000 \\
\hline
\end{tabular}

TABLE 3: Normalized influence relation matrix $\mathbf{D}=\left[d_{i j}\right]_{n \times n}$ obtained using the DEMATEL method.

\begin{tabular}{lcccccccccccc}
\hline D & LD & HS & FS & APU & SS & TS & FCS & CS & RDS & MS & RS \\
LD & 0.0000 & 0.0344 & 0.0496 & 0.0496 & 0.0916 & 0.0611 & 0.0344 & 0.0115 & 0.0115 & 0.0115 & 0.0115 & 0.0115 \\
HS & 0.1107 & 0.0000 & 0.1183 & 0.1145 & 0.0611 & 0.1069 & 0.1069 & 0.0534 & 0.0534 & 0.0954 & 0.0916 & 0.0878 \\
FS & 0.0802 & 0.1107 & 0.0000 & 0.0420 & 0.0382 & 0.0382 & 0.0420 & 0.0382 & 0.0382 & 0.0382 & 0.0382 & 0.0344 \\
APU & 0.1069 & 0.0916 & 0.0878 & 0.0000 & 0.0611 & 0.0878 & 0.0954 & 0.0573 & 0.0573 & 0.0878 & 0.0611 & 0.0305 \\
SS & 0.0725 & 0.0573 & 0.0649 & 0.0916 & 0.0000 & 0.0878 & 0.0687 & 0.0611 & 0.0573 & 0.0878 & 0.0878 & 0.0840 \\
TS & 0.0611 & 0.0840 & 0.0840 & 0.0878 & 0.0611 & 0.0000 & 0.0878 & 0.0305 & 0.0305 & 0.0573 & 0.0573 & 0.0573 \\
FCS & 0.0611 & 0.0649 & 0.0611 & 0.0916 & 0.0305 & 0.0611 & 0.0000 & 0.0916 & 0.1183 & 0.0954 & 0.0916 & 0.0878 \\
CS & 0.0382 & 0.0115 & 0.0305 & 0.0115 & 0.0573 & 0.0305 & 0.0954 & 0.0000 & 0.1298 & 0.0802 & 0.0802 & 0.0916 \\
RDS & 0.0344 & 0.0076 & 0.0267 & 0.0076 & 0.0534 & 0.0267 & 0.0916 & 0.1145 & 0.0000 & 0.0878 & 0.0878 & 0.0878 \\
MS & 0.0191 & 0.0534 & 0.0267 & 0.0534 & 0.0534 & 0.0305 & 0.0573 & 0.0305 & 0.0305 & 0.0000 & 0.0763 & 0.0763 \\
RS & 0.0191 & 0.0305 & 0.0267 & 0.0267 & 0.0534 & 0.0305 & 0.0305 & 0.0305 & 0.0305 & 0.0802 & 0.0000 & 0.0878 \\
GS & 0.0191 & 0.0267 & 0.0267 & 0.0267 & 0.0573 & 0.0305 & 0.0344 & 0.0267 & 0.0305 & 0.0802 & 0.0954 & 0.0000 \\
\hline
\end{tabular}

(0.8978, 0.1163), (0.8436, 0.0805), and $(0.8643,-0.1968)$, respectively. We then determine their directions based on the degree of total influence of the dimensions according to Table 4, which indicates that the total influence degree of the $D_{1}$ on $D_{2}$ is 0.1436 ; conversely, the total influence degree of $D_{2}$ on $D_{1}$ is 0.1205 . The directional arrow is then drawn from $D_{1}$ to $D_{2}$ because 0.1436 is greater than 0.1205 . The influence directions between all dimensions and factors are similarly determined and presented in Figure 3. As Figure 3 illustrates, the interinfluential relationships between the three dimensions are as follows: (1) $D_{1}$ influences $D_{2}$ and $D_{3}$, and (2) $D_{2}$ influence $D_{3}$. When adopting the same approach, the interinfluential effects visualized on the different tiers of the INRM reveal a structure that allows for analysis of the factors and dimensions that require enhanced scrutiny when determining strategies for improvement. 
TABLE 4: Total influence relation matrix of factors $\mathbf{T}, \mathbf{T}_{C}$ by factors, and $\mathbf{T}_{D}$ by dimensions, obtained using the DEMATEL method.

\begin{tabular}{|c|c|c|c|c|c|c|c|c|c|c|c|c|}
\hline $\mathrm{T}(\mathrm{T} C)$ & LD & HS & FS & APU & SS & TS & FCS & CS & RDS & MS & RS & GS \\
\hline LD & 0.0660 & 0.0958 & 0.1112 & 0.1131 & 0.1471 & 0.1208 & 0.1064 & 0.0661 & 0.0693 & 0.0906 & 0.0879 & 0.0833 \\
\hline HS & 0.2458 & 0.1398 & 0.2490 & 0.2481 & 0.2018 & 0.2361 & 0.2646 & 0.1752 & 0.1841 & 0.2704 & 0.2619 & 0.2485 \\
\hline FS & 0.1608 & 0.1805 & 0.0842 & 0.1255 & 0.1213 & 0.1196 & 0.1389 & 0.1090 & 0.1139 & 0.1427 & 0.1398 & 0.1311 \\
\hline APU & 0.2218 & 0.2018 & 0.2021 & 0.1238 & 0.1802 & 0.1998 & 0.2316 & 0.1613 & 0.1690 & 0.2360 & 0.2083 & 0.1743 \\
\hline SS & 0.1844 & 0.1664 & 0.1755 & 0.2015 & 0.1196 & 0.1943 & 0.2032 & 0.1611 & 0.1651 & 0.2346 & 0.2306 & 0.2193 \\
\hline TS & 0.1668 & 0.1820 & 0.1845 & 0.1900 & 0.1631 & 0.1044 & 0.2056 & 0.1232 & 0.1299 & 0.1907 & 0.1865 & 0.1786 \\
\hline FCS & 0.1743 & 0.1713 & 0.1717 & 0.1991 & 0.1530 & 0.1703 & 0.1447 & 0.1954 & 0.2258 & 0.2480 & 0.2408 & 0.2299 \\
\hline CS & 0.1189 & 0.0917 & 0.1109 & 0.0974 & 0.1457 & 0.1116 & 0.1950 & 0.0878 & 0.2103 & 0.1984 & 0.1971 & 0.2025 \\
\hline RDS & 0.1107 & 0.0844 & 0.1030 & 0.0898 & 0.1379 & 0.1039 & 0.1860 & 0.1856 & 0.0900 & 0.1989 & 0.1978 & 0.1940 \\
\hline MS & 0.0938 & 0.1214 & 0.0998 & 0.1262 & 0.1267 & 0.1030 & 0.1428 & 0.0976 & 0.1025 & 0.1019 & 0.1705 & 0.1651 \\
\hline RS & 0.0799 & 0.0892 & 0.0865 & 0.0895 & 0.1158 & 0.0902 & 0.1047 & 0.0862 & 0.0901 & 0.1607 & 0.0853 & 0.1619 \\
\hline GS & 0.0805 & 0.0867 & 0.0871 & 0.0903 & 0.1199 & 0.0909 & 0.1086 & 0.0836 & 0.0907 & 0.1619 & 0.1737 & 0.0823 \\
\hline $\mathbf{T}_{D}$ & \multicolumn{7}{|c|}{ Airframe $\left(D_{1}\right)$} & \multicolumn{2}{|c|}{ Electrics $\left(D_{2}\right)$} & \multicolumn{3}{|c|}{ Weapons $\left(D_{3}\right)$} \\
\hline Airframe $\left(D_{1}\right)$ & \multicolumn{7}{|c|}{0.1686} & \multicolumn{2}{|c|}{0.1463} & \multicolumn{3}{|c|}{0.1921} \\
\hline Electrics $\left(D_{2}\right)$ & \multicolumn{7}{|c|}{0.1205} & \multicolumn{2}{|c|}{0.1434} & \multicolumn{3}{|c|}{0.1981} \\
\hline Weapons $\left(D_{3}\right)$ & \multicolumn{7}{|c|}{0.1016} & \multicolumn{2}{|c|}{0.0918} & \multicolumn{3}{|c|}{0.1404} \\
\hline
\end{tabular}

Note. $I R=\left(1 / n^{2}\right) \sum_{i=1}^{n} \sum_{j=1}^{n}\left(\left|t_{i j}^{p}-t_{i j}^{p-1}\right| / t_{i j}^{p}\right) \times 100 \cong 1.16 \%<5 \%$, where $t_{i j}^{p}$ and $t_{i j}^{p-1}$ denote the average influence of the ith criterion on the jth criterion by the experts (samples) for $p=8$ and $p-1=7$, respectively, and $n=12$ denotes the number of factors or criteria. Thus, the results are significant at a confidence level of $98.84 \%$, which is greater than the $95 \%$ level used to test for significance.

TABLE 5: Total influence exerted and received for the dimensions and factors obtained using the DEMATEL method.

\begin{tabular}{|c|c|c|c|c|}
\hline Dimensions/factors & $r_{i}$ & $c_{i}$ & $r_{i}+c_{i}$ & $r_{i}-c_{i}$ \\
\hline Airframe $\left(D_{1}\right)$ & & & 0.8978 & 0.1163 \\
\hline $\mathrm{LD}\left(C_{1}\right)$ & 1.1575 & 1.7038 & 2.8613 & -0.5463 \\
\hline $\mathrm{HS}\left(C_{2}\right)$ & 2.7252 & 1.6111 & 4.3364 & 1.1141 \\
\hline $\mathrm{FS}\left(C_{3}\right)$ & 1.5673 & 1.6655 & 3.2328 & -0.0981 \\
\hline APU $\left(C_{4}\right)$ & 2.3099 & 1.6943 & 4.0042 & 0.6157 \\
\hline SS $\left(C_{5}\right)$ & 2.2556 & 1.7322 & 3.9878 & 0.5234 \\
\hline TS $\left(C_{6}\right)$ & 2.0055 & 1.6450 & 3.6505 & 0.3606 \\
\hline $\operatorname{FCS}\left(C_{7}\right)$ & 2.3244 & 2.0321 & 4.3565 & 0.2923 \\
\hline Electrics $\left(D_{2}\right)$ & & & 0.8436 & 0.0805 \\
\hline $\mathrm{CS}\left(C_{8}\right)$ & 1.7674 & 1.5321 & 3.2996 & 0.2353 \\
\hline $\mathrm{RDS}\left(C_{9}\right)$ & 1.6820 & 1.6407 & 3.3227 & 0.0413 \\
\hline Weapons $\left(D_{3}\right)$ & & & 0.8643 & -0.1968 \\
\hline $\operatorname{MS}\left(C_{10}\right)$ & 1.4514 & 2.2348 & 3.6862 & -0.7834 \\
\hline $\mathrm{RS}\left(C_{11}\right)$ & 1.2401 & 2.1802 & 3.4203 & -0.9400 \\
\hline GS $\left(C_{12}\right)$ & 1.2562 & 2.0709 & 3.3271 & -0.8148 \\
\hline
\end{tabular}

The values in bold are used to distinguish the total influence between dimensions and factors.

4.2.3. Computation of IWs Using DANP. After the establishment of the INRM, the expert team normalizes the total influence relation matrix of factors and dimensions by using equations (7), (8), (11), and (12), as exhibited in Table 6. Additionally, the expert team transposes the matrices in Table 6 to an unweighted supermatrix by using equations (9) and (10) and then uses equation (13) to obtain a weighted supermatrix, as illustrated in Table 7. Finally, the buyer multiplies the weighted super matrix until it converges into a steady-state condition, with the IWs for the factors and dimensions, as presented in Table 8.

4.2.4. Measurement of Gap Indices Based on the Modified VIKOR Method. During this stage, based on Table 1, the buyer sets the worst-case value $f_{j}^{\text {worst }}$ and best-case value $f_{j}^{\text {aspired }}$ (aspired level) to analyze the three supportability levels, which are denoted by $A_{1}, A_{2}$, and $A_{3}$. Subsequently, the buyer uses the IWs from DANP together with the modified VIKOR method to compute the gap indices for the three alternatives and their dimensions and factors by using equations (14)-(18). The computational results, which are summarized in Table 9, reveal the extent to which each alternative, dimension, and factor would need to be improved to reach the respective aspiration levels. Based on Table 9, the expert team aggregates the gap indices on the INRM (Figure 3) and arranges meetings including those with external participants to discuss actionable ways to eliminate the gaps. All participants review Tables 1-9 with reference to the INRM to realize the extent of the gaps that require bridging. The meeting results provide the buyer with valuable insights regarding the provision of alternative methods to finalize the improvement solutions with the seller. Table 10 presents an example to illustrate how the different types of information produced by the proposed procedure are used to 


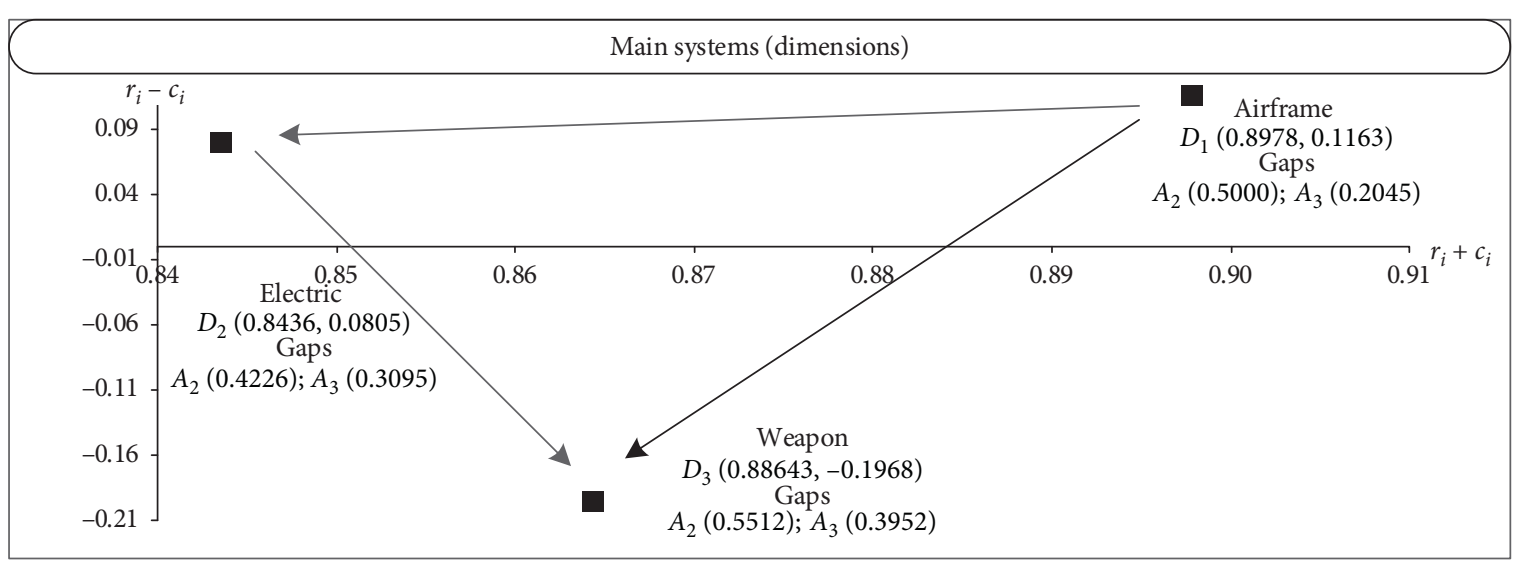

(a)

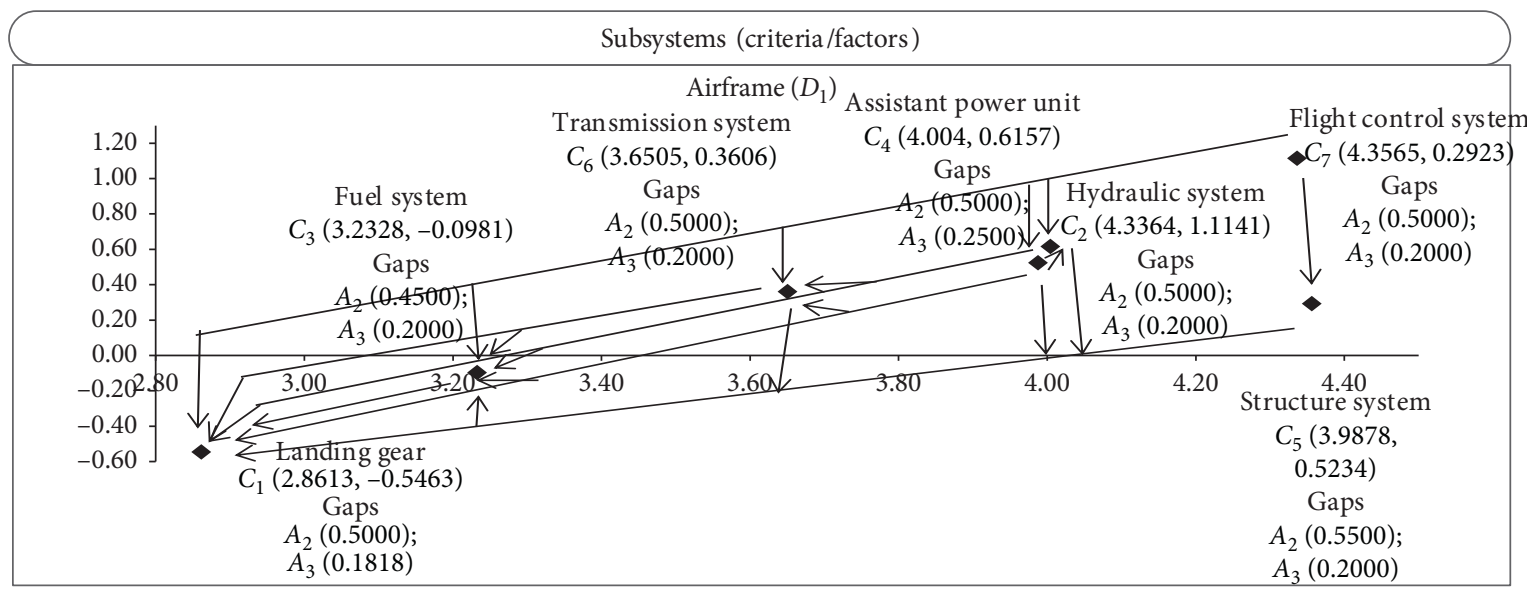

(b)

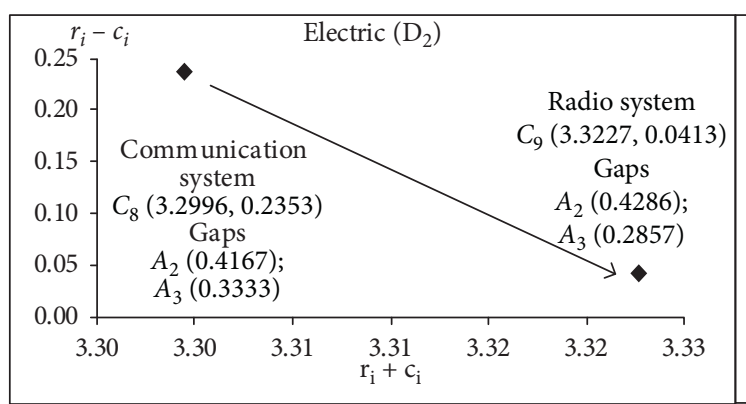

(c)

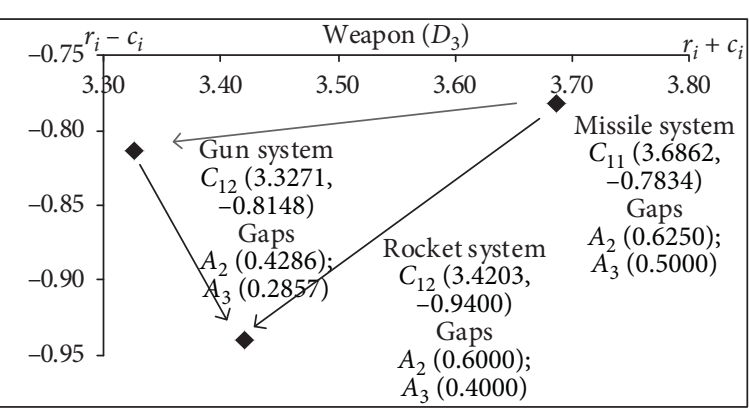

(d)

FIgURE 3: Influential network relation map.

determine the improvement proposals, which also provides the buyer with a basis on which to iterate the proposed procedure in the postnegotiation phase to implement continuous improvements.

\section{Discussion and Implications}

This study derives several critical results concerning improvements to suboptimal PN agreements. First, according to Table 5, using the DEMATEL method to evaluate the interinfluential effects between the criteria and dimensions associated with the negotiated PN agreement can yield valuable information to assist managers to systematically understand suboptimal situations at different levels. This understanding provides managers with insight into the identification of the critical subsystems and systems that should be prioritized for improvement. For example, in the DEMATEL results illustrated in Table 5 , the $\left(r_{i}+c_{i}, r_{i}-c_{i}\right)$ values at the dimension level are $(0.8978,0.1163)$ for $D_{1}$, $(0.8436,0.0805)$ for $D_{2}$, and $(0.8643,-0.1968)$ for $D_{3}$. In these values, the $r_{i}+c_{i}$ values indicate that the expert team members generally agreed that all three main systems are central to achieving the desired supportability. Additionally, according to the $r_{i}-c_{i}$ values, $D_{1}$ influences $D_{2}$ and $D_{3}$, and $D_{2}$ influences $D_{3}$, implying that improvements to the airframe $\left(D_{1}\right)$ should contribute the greatest improvement to the overall supportability, followed by improvements to the electronics system $\left(D_{2}\right)$ and the weapons system $\left(D_{3}\right)$. 
TABLE 6: Normalized total influence relation matrix of factors $\mathbf{T}_{C}^{\alpha}$ and dimensions $\mathbf{T}_{D}^{\alpha}$ derived using DANP.

\begin{tabular}{|c|c|c|c|c|c|c|c|c|c|c|c|c|}
\hline $\mathbf{T}_{C}^{\alpha}$ & LD & $\mathrm{HS}$ & FS & APU & SS & TS & FCS & CS & RDS & MS & RS & GS \\
\hline LD & 0.0869 & 0.1260 & 0.1463 & 0.1487 & 0.1934 & 0.1589 & 0.1399 & 0.4880 & 0.5120 & 0.3460 & 0.3359 & 0.3180 \\
\hline HS & 0.1550 & 0.0882 & 0.1571 & 0.1565 & 0.1273 & 0.1489 & 0.1669 & 0.4876 & 0.5124 & 0.3463 & 0.3354 & 0.3183 \\
\hline FS & 0.1728 & 0.1939 & 0.0904 & 0.1348 & 0.1303 & 0.1285 & 0.1492 & 0.4891 & 0.5109 & 0.3449 & 0.3380 & 0.3171 \\
\hline APU & 0.1630 & 0.1483 & 0.1485 & 0.0910 & 0.1324 & 0.1468 & 0.1701 & 0.4883 & 0.5117 & 0.3815 & 0.3367 & 0.2818 \\
\hline SS & 0.1481 & 0.1336 & 0.1410 & 0.1618 & 0.0961 & 0.1561 & 0.1632 & 0.4939 & 0.5061 & 0.3428 & 0.3369 & 0.3203 \\
\hline TS & 0.1394 & 0.1521 & 0.1542 & 0.1588 & 0.1364 & 0.0873 & 0.1719 & 0.4868 & 0.5132 & 0.3431 & 0.3355 & 0.3214 \\
\hline FCS & 0.1472 & 0.1446 & 0.1450 & 0.1681 & 0.1292 & 0.1438 & 0.1222 & 0.4639 & 0.5361 & 0.3451 & 0.3350 & 0.3199 \\
\hline CS & 0.1365 & 0.1053 & 0.1272 & 0.1118 & 0.1672 & 0.1281 & 0.2239 & 0.2945 & 0.7055 & 0.3317 & 0.3296 & 0.3386 \\
\hline RDS & 0.1357 & 0.1035 & 0.1262 & 0.1101 & 0.1691 & 0.1274 & 0.2280 & 0.6733 & 0.3267 & 0.3367 & 0.3348 & 0.3285 \\
\hline MS & 0.1153 & 0.1492 & 0.1227 & 0.1551 & 0.1557 & 0.1266 & 0.1755 & 0.4878 & 0.5122 & 0.2329 & 0.3897 & 0.3774 \\
\hline $\mathrm{RS}$ & 0.1219 & 0.1361 & 0.1319 & 0.1365 & 0.1766 & 0.1375 & 0.1596 & 0.4891 & 0.5109 & 0.3940 & 0.2092 & 0.3969 \\
\hline GS & 0.1212 & 0.1306 & 0.1312 & 0.1361 & 0.1806 & 0.1369 & 0.1635 & 0.4798 & 0.5202 & 0.3874 & 0.4156 & 0.1970 \\
\hline$\overline{\mathbf{T}_{D}^{\alpha}}$ & \multicolumn{7}{|c|}{ Airframe $\left(D_{1}\right)$} & \multicolumn{2}{|c|}{ Electrics $\left(D_{2}\right)$} & \multicolumn{3}{|c|}{ Weapons $\left(D_{3}\right)$} \\
\hline Airframe $\left(D_{1}\right)$ & \multicolumn{7}{|c|}{0.3326} & \multicolumn{2}{|c|}{0.2886} & \multicolumn{3}{|c|}{0.3788} \\
\hline Electrics $\left(D_{2}\right)$ & \multicolumn{7}{|c|}{0.2608} & \multicolumn{2}{|c|}{0.3104} & \multicolumn{3}{|c|}{0.4288} \\
\hline Weapons $\left(D_{3}\right)$ & \multicolumn{7}{|c|}{0.3044} & \multicolumn{2}{|c|}{0.2750} & \multicolumn{3}{|c|}{0.4206} \\
\hline
\end{tabular}

TABLE 7: Unweighted and weighted supermatrices $\mathbf{W}=\left(\mathbf{T}_{C}^{\alpha}\right)^{\prime}$ and $\mathbf{W}^{\alpha}=\mathbf{T}_{D}^{\alpha} \mathbf{W}$ derived using DANP.

\begin{tabular}{|c|c|c|c|c|c|c|c|c|c|c|c|c|}
\hline $\mathrm{W}$ & LD & HS & FS & APU & SS & TS & FCS & CS & RDS & MS & $\mathrm{RS}$ & GS \\
\hline LD & 0.0279 & 0.0497 & 0.0554 & 0.0523 & 0.0475 & 0.0447 & 0.0472 & 0.0319 & 0.0317 & 0.0335 & 0.0354 & 0.0352 \\
\hline HS & 0.0404 & 0.0283 & 0.0622 & 0.0476 & 0.0429 & 0.0488 & 0.0464 & 0.0246 & 0.0242 & 0.0433 & 0.0395 & 0.0380 \\
\hline FS & 0.0469 & 0.0504 & 0.0290 & 0.0476 & 0.0452 & 0.0495 & 0.0465 & 0.0297 & 0.0295 & 0.0356 & 0.0383 & 0.0381 \\
\hline APU & 0.0477 & 0.0502 & 0.0432 & 0.0292 & 0.0519 & 0.0509 & 0.0539 & 0.0261 & 0.0257 & 0.0451 & 0.0397 & 0.0395 \\
\hline SS & 0.0620 & 0.0408 & 0.0418 & 0.0425 & 0.0308 & 0.0437 & 0.0414 & 0.0390 & 0.0395 & 0.0452 & 0.0513 & 0.0525 \\
\hline TS & 0.0510 & 0.0478 & 0.0412 & 0.0471 & 0.0501 & 0.0280 & 0.0461 & 0.0299 & 0.0297 & 0.0368 & 0.0399 & 0.0398 \\
\hline FCS & 0.0449 & 0.0535 & 0.0479 & 0.0546 & 0.0524 & 0.0551 & 0.0392 & 0.0523 & 0.0532 & 0.0510 & 0.0464 & 0.0475 \\
\hline CS & 0.1502 & 0.1501 & 0.1506 & 0.1503 & 0.1520 & 0.1499 & 0.1428 & 0.1006 & 0.2299 & 0.1446 & 0.1450 & 0.1422 \\
\hline RDS & 0.1576 & 0.1577 & 0.1573 & 0.1575 & 0.1558 & 0.1580 & 0.1650 & 0.2409 & 0.1115 & 0.1518 & 0.1515 & 0.1542 \\
\hline MS & 0.1285 & 0.1286 & 0.1281 & 0.1417 & 0.1273 & 0.1274 & 0.1282 & 0.1410 & 0.1431 & 0.0962 & 0.1627 & 0.1600 \\
\hline $\mathrm{RS}$ & 0.1248 & 0.1246 & 0.1255 & 0.1250 & 0.1251 & 0.1246 & 0.1244 & 0.1401 & 0.1423 & 0.1609 & 0.0864 & 0.1717 \\
\hline GS & 0.1181 & 0.1182 & 0.1178 & 0.1047 & 0.1190 & 0.1194 & 0.1188 & 0.1439 & 0.1396 & 0.1558 & 0.1639 & 0.0814 \\
\hline $\mathbf{W}^{\alpha}$ & LD & HS & FS & APU & SS & TS & FCS & CS & RDS & MS & $\mathrm{RS}$ & GS \\
\hline $\mathrm{LD}$ & 0.0379 & 0.0375 & 0.0373 & 0.0373 & 0.0375 & 0.0377 & 0.0376 & 0.0364 & 0.0364 & 0.0375 & 0.0373 & 0.0373 \\
\hline HS & 0.0372 & 0.0374 & 0.0364 & 0.0370 & 0.0371 & 0.0370 & 0.0370 & 0.0360 & 0.0361 & 0.0367 & 0.0370 & 0.0372 \\
\hline FS & 0.0374 & 0.0373 & 0.0378 & 0.0373 & 0.0375 & 0.0373 & 0.0374 & 0.0365 & 0.0365 & 0.0375 & 0.0372 & 0.0373 \\
\hline APL & 0.0384 & 0.0383 & 0.0385 & 0.0388 & 0.0382 & 0.0383 & 0.0382 & 0.0376 & 0.0377 & 0.0382 & 0.0386 & 0.0386 \\
\hline SS & 0.0439 & 0.0445 & 0.0446 & 0.0445 & 0.0446 & 0.0444 & 0.0445 & 0.0446 & 0.0445 & 0.0448 & 0.0444 & 0.0443 \\
\hline TS & 0.0377 & 0.0378 & 0.0381 & 0.0378 & 0.0377 & 0.0382 & 0.0378 & 0.0371 & 0.0372 & 0.0380 & 0.0378 & 0.0378 \\
\hline FCS & 0.0503 & 0.0500 & 0.0501 & 0.0500 & 0.0500 & 0.0500 & 0.0502 & 0.0499 & 0.0498 & 0.0498 & 0.0501 & 0.0500 \\
\hline CS & 0.1528 & 0.1527 & 0.1527 & 0.1527 & 0.1524 & 0.1527 & 0.1537 & 0.1614 & 0.1447 & 0.1522 & 0.1522 & 0.1527 \\
\hline RDS & 0.1612 & 0.1612 & 0.1613 & 0.1613 & 0.1615 & 0.1612 & 0.1602 & 0.1530 & 0.1698 & 0.1609 & 0.1609 & 0.1603 \\
\hline MS & 0.1370 & 0.1370 & 0.1370 & 0.1359 & 0.1372 & 0.1371 & 0.1371 & 0.1383 & 0.1379 & 0.1403 & 0.1358 & 0.1362 \\
\hline RS & 0.1353 & 0.1353 & 0.1352 & 0.1351 & 0.1352 & 0.1353 & 0.1353 & 0.1370 & 0.1365 & 0.1343 & 0.1399 & 0.1327 \\
\hline GS & 0.1311 & 0.1310 & 0.1312 & 0.1323 & 0.1310 & 0.1309 & 0.1309 & 0.1321 & 0.1330 & 0.1299 & 0.1288 & 0.1356 \\
\hline
\end{tabular}

TABLE 8: $\lim _{Z \longrightarrow \infty}\left(\mathbf{W}^{\alpha}\right)^{Z}$ and IWs obtained using DANP.

\begin{tabular}{lcccccccccccc}
\hline $\lim _{Z \longrightarrow \infty}\left(\mathbf{W}^{\alpha}\right)^{Z}$ & LD & HS & FS & APU & SS & TS & FCS & CS & RDS & MS & RS & GS \\
\hline LD & 0.0371 & 0.0371 & 0.0371 & 0.0371 & 0.0371 & 0.0371 & 0.0371 & 0.0371 & 0.0371 & 0.0371 & 0.0371 & 0.0371 \\
HS & 0.0367 & 0.0367 & 0.0367 & 0.0367 & 0.0367 & 0.0367 & 0.0367 & 0.0367 & 0.0367 & 0.0367 & 0.0367 & 0.0367 \\
FS & 0.0371 & 0.0371 & 0.0371 & 0.0371 & 0.0371 & 0.0371 & 0.0371 & 0.0371 & 0.0371 & 0.0371 & 0.0371 & 0.0371 \\
APU & 0.0382 & 0.0382 & 0.0382 & 0.0382 & 0.0382 & 0.0382 & 0.0382 & 0.0382 & 0.0382 & 0.0382 & 0.0382 & 0.0382 \\
SS & 0.0445 & 0.0445 & 0.0445 & 0.0445 & 0.0445 & 0.0445 & 0.0445 & 0.0445 & 0.0445 & 0.0445 & 0.0445 & 0.0445 \\
TS & 0.0376 & 0.0376 & 0.0376 & 0.0376 & 0.0376 & 0.0376 & 0.0376 & 0.0376 & 0.0376 & 0.0376 & 0.0376 & 0.0376 \\
FCS & 0.0500 & 0.0500 & 0.0500 & 0.0500 & 0.0500 & 0.0500 & 0.0500 & 0.0500 & 0.0500 & 0.0500 & 0.0500 & 0.0500 \\
CS & 0.1526 & 0.1526 & 0.1526 & 0.1526 & 0.1526 & 0.1526 & 0.1526 & 0.1526 & 0.1526 & 0.1526 & 0.1526 & 0.1526 \\
RDS & 0.1611 & 0.1611 & 0.1611 & 0.1611 & 0.1611 & 0.1611 & 0.1611 & 0.1611 & 0.1611 & 0.1611 & 0.1611 & 0.1611 \\
\hline
\end{tabular}


TABLE 8: Continued.

\begin{tabular}{|c|c|c|c|c|c|c|c|c|c|c|c|c|}
\hline $\lim _{Z \longrightarrow \infty}\left(\mathbf{W}^{\alpha}\right)^{Z}$ & LD & HS & FS & APU & SS & TS & FCS & CS & RDS & MS & RS & GS \\
\hline MS & 0.1375 & 0.1375 & 0.1375 & 0.1375 & 0.1375 & 0.1375 & 0.1375 & 0.1375 & 0.1375 & 0.1375 & 0.1375 & 0.1375 \\
\hline RS & 0.1359 & 0.1359 & 0.1359 & 0.1359 & 0.1359 & 0.1359 & 0.1359 & 0.1359 & 0.1359 & 0.1359 & 0.1359 & 0.1359 \\
\hline GS & 0.1317 & 0.1317 & 0.1317 & 0.1317 & 0.1317 & 0.1317 & 0.1317 & 0.1317 & 0.1317 & 0.1317 & 0.1317 & 0.1317 \\
\hline IWs & LD & HS & FS & APU & SS & TS & FCS & $\mathrm{CS}$ & RDS & MS & $\mathrm{RS}$ & GS \\
\hline Local & 0.0371 & 0.0367 & 0.0371 & 0.0382 & 0.0445 & 0.0376 & 0.0500 & 0.1526 & 0.1611 & 0.1375 & 0.1359 & 0.1317 \\
\hline \multirow[t]{2}{*}{ Global } & LD & HS & FS & $\begin{array}{c}\text { Airframe } \\
\text { APU } \\
\mathbf{0 . 2 8 1 2}\end{array}$ & SS & TS & FCS & $\begin{array}{c}\text { Ele } \\
\text { CS } \\
\mathbf{0 .}\end{array}$ & $\begin{array}{l}\text { rics } \\
\text { RDS } \\
37\end{array}$ & MS & $\begin{array}{c}\text { Weapons } \\
\text { RS } \\
\mathbf{0 . 4 0 5 1}\end{array}$ & GS \\
\hline & 0.1319 & 0.1305 & 0.1319 & 0.1358 & 0.1583 & 0.1337 & 0.1778 & 0.4865 & 0.5135 & 0.3394 & 0.3355 & 0.3251 \\
\hline
\end{tabular}

The values in bold are used to distinguish the IWs between dimensions and factors.

TABLE 9: Gap indices for factors, dimensions, and alternatives obtained using the modified VIKOR method.

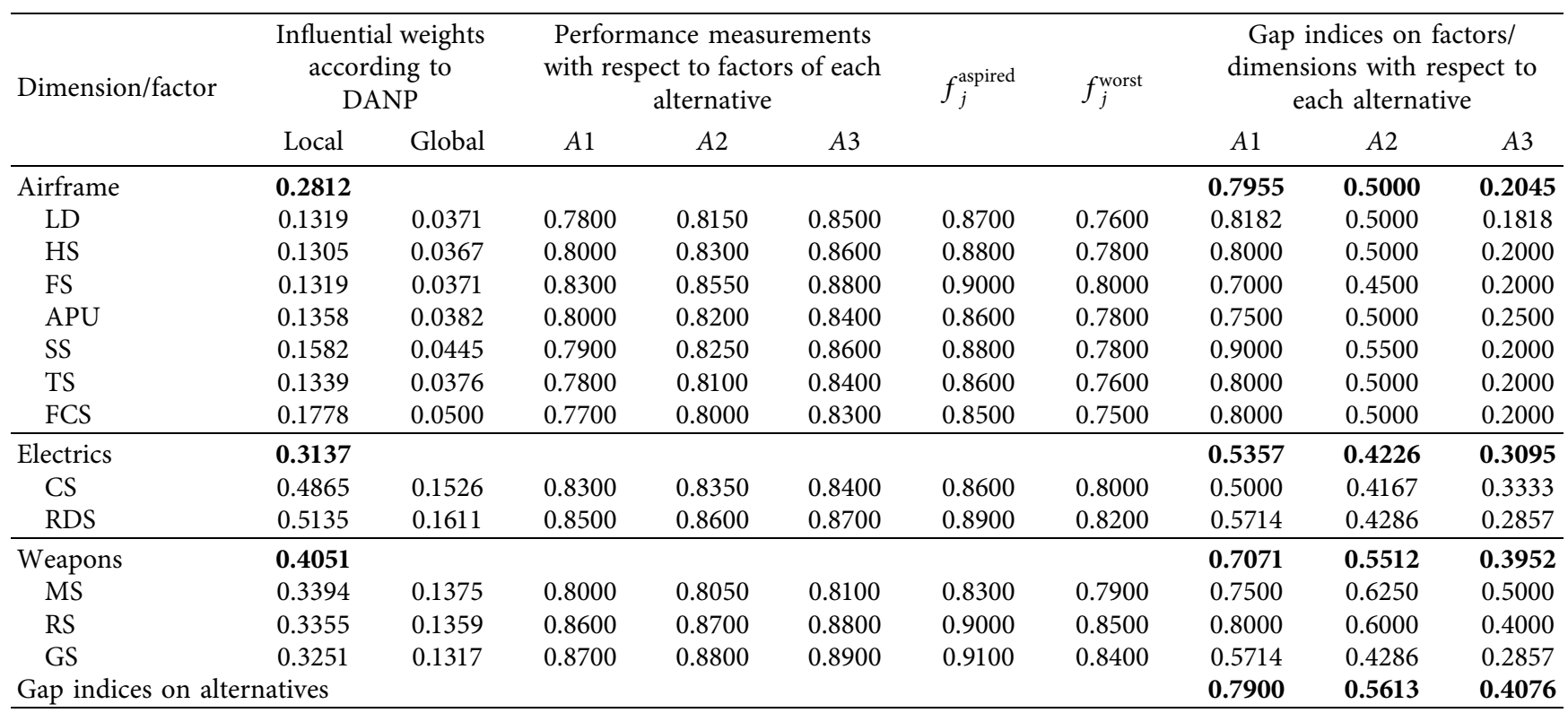

The values in bold are used to distinguish the influential weights and the gap indices between dimensions and factors.

TABLE 10: Example of determining an improvement proposal.

\begin{tabular}{lccr}
\hline Options & Levels & Proposals & Main consideration \\
\hline \multirow{2}{*}{1} & Dimensions & Weapons $\left(D_{3}\right) \prec$ Airframe $\left(D_{1}\right) \prec$ Electrics $\left(D_{2}\right)$ & Performance gap size \\
& Criteria & MS $\left(C_{10}\right) \prec \mathrm{RS}\left(C_{11}\right) \prec \mathrm{SS}\left(C_{5}\right) \prec$ HS $\left(C_{2}\right) \prec$ FCS & Degree of centrality \\
\hline \multirow{2}{*}{2} & Dimensions & Airframe $\left(D_{1}\right) \prec$ Weapons $\left(D_{3}\right) \prec$ Electrics $\left(D_{2}\right)$ & Criteria \\
\hline
\end{tabular}

Following this approach allows for the level of interinfluence between the factors to be understood. As revealed in Table 5, between the 12 subsystems, the hydraulics system (HS, $C_{2} 4.3364,1.1141$ ), the assistant power units (APU, $\left.C_{4} 4.0042,0.6157\right)$, and the flight control system (FCS, $\left.C_{7} \_4.3565,0.2923\right)$ are the most critical subsystems for improving overall supportability. This reflects the facts that (1) they have higher role centrality than the other factors do, and (2) their net influences are positive.

Because each evaluation dimension and criterion produce essential information for improving negotiated agreements, we strongly suggest that managers use the
DEMATEL method to evaluate the interdependencies among the dimensions and criteria of negotiated agreements during their implementation. In addition, as presented in Table 6, the interrelationships generated from the DEMATEL method can also be used as input data for DANP to derive the IWs for each criterion and dimension. Although the assumption of most decision-making methodologies regarding mutual exclusivity and independence on the decision variables may not hold in a $\mathrm{PN}$ setting, the proposed procedure employs DANP to enable interdependent negotiation situations to be considered in the decision process and outcomes of the PN setting. 
The results of the case study also reveal that combining DANP with the modified VIKOR method can help the buyer gain insights into practical methods to solve suboptimality problems. For example, the proposed procedure measures gap indices in both the main systems (the three dimensions) and the subsystems (12 factors) under the respective alternatives (Table 9). These measurements provide the buyer with additional options when formulating improvement proposals. Taking $A_{2}$ as an example (Table 9), the gap indices in the dimension and factor levels indicate that the weapons system $\left(D_{3}\right)$ and its subsystems (i.e., the missile system (MS) and the rocket system (RS)) should be prioritized when determining improvement proposals because of their substantial aspiration level gaps compared with those of the other main systems and subsystems. This finding differs from the implications of the DEMATEL results (Table 5), in which it is assumed that improving the airframe $\left(D_{1}\right)$ should be prioritized. For the buyer, the additional information obtained from the gap indices provides for increased options and flexibility when determining improvement proposals before negotiating with the seller to produce sustainable improvement solutions. For example, in Table 10, option 1 of the improvement proposals is based first on the performance gap size and then on the role centrality. By contrast, option 2 is considered differently. Consideration of the different types of information produced from the proposed procedure can result in various improvement effects and priorities for the main systems and subsystems, which, in turn, provide the buyer with increased flexibility to prepare and pursue the aspired PN outcomes.

The proposed procedure also enables the different tiers of the interinfluential effects and the gap indices to be systemized and visualized in an INRM. The INRM provides the PN participants with a solid basis to manage the dynamics of improvement situations that arise during an agreement's implementation lifecycle. According to Table 9 , when the supportability level is increased to $A_{3}$, the sequence of the dimension-level gap indices differs from that of $A_{2}$, which indicates that the organizations have different perspectives on implementation. Therefore, periodic meetings between the parties are essential. The INRM (Figure 3) is updated by the buyer before each meeting by comparing the undated total influence effects between each dimension and factor. The buyer is then able to inform the seller about the main systems and subsystems that should be prioritized. For example, as exhibited in Figure 3, from the weapons system perspective, the seller should prioritize the MS because maintaining its supportability would positively influence both the gun system (GS) and the RS. By assisting parties to understand their own requirements and by providing alternatives and possible solutions to share with the opposite party, the proposed procedure can ensure practical settlement of negotiated agreements in a PN setting.

\section{Conclusions and Remarks}

Complicated PNs are usually concluded at a suboptimal level. This study proposes a novel procedure, based on a combined MADM model to help managers create postnegotiation settlements over an agreement's implementation lifecycle.

A numerical example of a logistics service project demonstrates the proposed procedure's merits: (1) interinfluential effects and gap indices are used to support improvement strategies in the pursuit of aspired outcomes regardless of how and why a suboptimal agreement initially occurs; (2) managers obtain detailed and systematic information on a visualized map to identify the core issues causing suboptimality PN problems; and (3) it extends on previous studies of improving negotiated agreements from the conceptual level to a practical operational level. These merits indicate that the proposed procedure can provide a valuable foundation for solving suboptimal agreement problems in the PN setting.

However, this study also has several limitations. First, its conclusions are based on a procurement project between a public organization and private contractor in the case study country. Future research could apply our procedure to other settings, such as those occurring across countries and organizations in different industries, to examine how our procedure functions over a wide range of procurement situations. The resulting comparisons could offer more insights into the applicability of the proposed procedure. Second, the improvement proposals addressed in the example only comprise principle concepts. Future research could be undertaken to identify substantial aspects for improvement. Such work could be formulated as a design problem, and future research could adopt multiple criteria decision-making methods such as the de novo programming for multiple objective decision-making, which might provide valuable results for improving negotiated agreements with changeable objectives and decision spaces. Finally, the proposed procedure assumes that negotiating parties are willing to work cooperatively to resolve suboptimality problems after the negotiated agreement is concluded. In reality, incentives could be applied to the proposed procedure so that it functions more pragmatically to enhance the efficiency and effectiveness of the initial negotiations. Integrating practical incentives and flexible contractual mechanisms to motivate procurement agreement participants to pursue continuous improvement solutions also deserves further study.

\section{Data Availability}

The numerical data used to support the findings of this study are included within the article.

\section{Disclosure}

The sponsors had no role in the design of the study; in the collection, analysis, or interpretation of the data; in the writing of the manuscript; or in the decision to publish.

\section{Conflicts of Interest}

The authors declare no conflicts of interest. 


\section{Acknowledgments}

This research was funded by Sanming University, Fujian, China, grant number KD190013.

\section{References}

[1] P. Baily, D. Farmer, D. Jessop, and D. Jones, Purchasing Principle and Management, Pearson Education Limited, London, UK, 2005.

[2] M. Skaates, H. Tikkanen, and J. Lindblom, "Relationships and project marketing success," Journal of Business \& Industrial Marketing, vol. 17, no. 5, pp. 389-406, 2002.

[3] J. Kujala, J. Murtoaro, and K. Artto, "A negotiation approach to project sales and implementation," Project Management Journal, vol. 38, no. 4, pp. 33-44, 2007.

[4] W. Zartman, "Negotiation as a joint decision-making process," Journal of Conflict Resolution, vol. 21, no. 4, pp. 619-638, 1977.

[5] J. Murtoaro and J. Kujala, "Project negotiation analysis," International Journal of Project Management, vol. 25, no. 7, pp. 722-733, 2007.

[6] R. Fisher, W. Ury, and B. Patton, Getting to Yes: Negotiating Agreement without Giving in, Penguin, New York, NY, USA, 2011.

[7] J. K. Sebenius, "Negotiation analysis: from games to inferences to decisions to deals," Negotiation Journal, vol. 25, no. 4, pp. 449-465, 2009.

[8] R.-J. Dzeng and Y.-C. Lin, "Intelligent agents for supporting construction procurement negotiation," Expert Systems with Applications, vol. 27, no. 1, pp. 107-119, 2004.

[9] H. Ehtamo and R. P. Hämäläinen, "Interactive multiple criteria methods for reaching Pareto optimal agreements in negotiations," Group Decision and Negotiation, vol. 10, no. 6, pp. 475-491, 2001.

[10] L. Wang, L. Fang, and K. W. Hipel, "Negotiation over costs and benefits in brownfield redevelopment," Group Decision and Negotiation, vol. 20, no. 4, pp. 509-524, 2011.

[11] D. Ertel, "Getting past yes: negotiating as if implementation mattered," Harvard Business Review, vol. 82, no. 11, pp. 60148, 2004.

[12] J. R. Turner and A. Keegan, "Mechanisms of governance in the project-based organization: roles of the broker and steward," European Management Journal, vol. 19, no. 3, pp. 254-267, 2001.

[13] R. Lewicki and A. Hiam, Mastering Business Negotiation: A Working Guide to Making Deals and Resolving Conflict, John Wiley \& Sons, Hoboken, NJ, USA, 2011.

[14] I. Mosterd and C. G. Rutte, "Effects of time pressure and accountability to constituents on negotiation," International Journal of Conflict Management, vol. 11, no. 3, pp. 227-247, 2000.

[15] C. K. W. De Dreu, "Time pressure and closing of the mind in negotiation," Organizational Behavior and Human Decision Processes, vol. 91, no. 2, pp. 280-295, 2003.

[16] J.-B. Yang, C.-C. Yang, and C.-K. Kao, "Evaluating schedule delay causes for private participating public construction works under the build-operate-transfer model," International Journal of Project Management, vol. 28, no. 6, pp. 569-579, 2010.

[17] H. Raiffa, "Post-settlement settlements," Negotiation Journal, vol. 1, no. 1, pp. 9-12, 1985.

[18] L. Susskind, "Balancing analysis and intuition," Negotiation Journal, vol. 33, no. 4, 2017.
[19] W. W. Baber, "Identifying macro phases across the negotiation lifecycle," Group Decision and Negotiation, vol. 27, pp. 885-903, 2018.

[20] R. Smolinski and Y. Xiong, "In search of master negotiators: a negotiation competency model," Negotiation Journal, vol. 36, no. 3, pp. 365-388, 2020.

[21] J. J. H. Liou, "New concepts and trends of mcdm for tomorrow-in honor of professor Gwo-Hshiung Tzeng on the occasion of his 70th birthday," Technological and Economic Development of Economy, vol. 19, no. 2, pp. 367-375, 2013.

[22] K.-H. Peng and G.-H. Tzeng, "A hybrid dynamic MADM model for problem-improvement in economics and business," Technological and Economic Development of Economy, vol. 19, no. 4, pp. 638-660, 2013.

[23] K.-H. Hu, F.-H. Chen, and G.-H. Tzeng, "Evaluating the improvement of sustainability of sports industry policy based on MADM," Sustainability, vol. 8, no. 7, p. 606, 2016.

[24] Y. Liu, Y. Yang, Y. Liu, and G.-H. Tzeng, "Improving sustainable mobile health care promotion: a novel hybrid mcdm method," Sustainability, vol. 11, no. 3, p. 752, 2019.

[25] B.-W. Zhu, Z. Huang, and L. Xiong, "Application of the Kano model and DEMATEL technique to explore sustainable promotion strategies for Thai-Chinese temples as tourist attractions," Religions, vol. 11, no. 4, p. 199, 2020.

[26] J. Liu and C. Y. J. Cheah, "Real option application in PPP/PFI project negotiation," Construction Management and Economics, vol. 27, no. 4, pp. 331-342, 2009.

[27] M. Olekalns, J. M. Brett, and L. R. Weingart, "Phases, transitions and interruptions: modeling processes in multi-party negotiations," International Journal of Conflict Management, vol. 14, no. 3/4, pp. 191-211, 2003.

[28] R.-L. Keeney and H. Raiffa, Decisions with Multiple Objectives: Preference and Value Tradeoffs, Cambridge University Press, Cambridge, UK, 1976.

[29] A. Rubinstein, "Perfect equilibrium in a bargaining model," Econometrica, vol. 50, no. 1, pp. 97-109, 1982.

[30] B. I. Spector, "Decision analysis for practical negotiation application," Theory and Decision, vol. 34, no. 3, pp. 183-199, 1993.

[31] J. Teich, H. Wallenius, and J. Wallenius, "Advances in negotiation science," Transactions on Operational Research, vol. 6, pp. 55-94, 1994.

[32] C. Holsapple, H. Lai, and A. Whinston, "Implications of negotiation theory for research and development of negotiation support systems," Group Decision and Negotiation, vol. 6, no. 3, pp. 255-274, 1997.

[33] G.-H. Tzeng and J.-H. Huang, Multiple Attribute Decision Making Methods and Applications, CRC Press, Boca Raton, FL, USA, 2011.

[34] A. Gabus and E. Fontela, World Problems: an Invitation to Further Thought within the Framework of DEMATEL, Battelle Geneva Research Center, Geneva, Switzerland, 1972.

[35] T. Saaty, Decision Making with Dependence and Feedback: The Analytic Networking Process, Vol. 4922, RWS Publications, Pittsburgh, PA, USA, 1996.

[36] S. Opricovic and G.-H. Tzeng, "Extended VIKOR method in comparison with outranking methods," European Journal of Operational Research, vol. 178, no. 2, pp. 514-529, 2007.

[37] H. A. Simon, "A behavioral model of rational choice," The Quarterly Journal of Economics, vol. 69, no. 1, pp. 99-118, 1955.

[38] Y. Chen, G. Kersten, R. Vetschera, and H. Xu, "Group decision and negotiation in an uncertain world," in Proceedings of the GDN 2018, Nanjing, China, June 2018. 
[39] C. Morais, A. Carreras, T. de Almeida, and R. Vetschera, "Group decision and negotiation: behavior, models, and support," in Proceedings of the 19th International Conference GDN 2019, Loughborough, UK, June 2019.

[40] A. Frej, T. de Almeida, and R. Roselli, "Solving multicriteria group decision-making (MCGDM) problems based on ranking with partial information," in Proceedings of the GDN 2019, Loughborough, UK, June 2019.

[41] S. Sakr, A. Liu, D. M. Batista, and M. Alomari, "A survey of large scale data management approaches in cloud environments," IEEE Communications Surveys \& Tutorials, vol. 13, no. 3, pp. 311-336, 2011.

[42] S. Opricovic, Multicriteria optimization of civil engineering systems, Ph.D. thesis, Faculty of Civil Engineering, University of Belgrade, Belgrade, Serbia, 1998.

[43] M. Freimer and P. L. Yu, "Some new results on compromise solutions for group decision problems," Management Science, vol. 22, no. 6, pp. 688-693, 1976.

[44] S.-Y. Chou, C.-C. Yu, and G.-H. Tzeng, "A novel hybrid MCDM procedure for achieving aspired earned value project performance," Mathematical Problems in Engineering, vol. 2016, Article ID 9721726, 16 pages, 2016. 